\title{
El “Rey Católico” DE las PRIMERAs guerras DE ItALIA. IMAGEN DE FERnANDO II DE ARAgÓN Y V DE CASTILLA ENTRE LA EXPECTACIÓN PROFÉTICA Y LA TENSIÓN INTERNACIONAL (1493-1499)
}

\author{
Álvaro Fernández de Córdova Miralless* \\ Universidad de Navarra
}

\begin{abstract}
Resumen
En el último decenio del siglo XV la imagen de Fernando el Católico adquirió una dimensión europea definida por sus relaciones con el Papado, los proyectos de expansión mediterránea y el conflicto con Francia por el reino de Nápoles. En el presente trabajo pretendemos reconstruir la trayectoria -no siempre ascendente- de este icono político a través del juicio de los cronistas, la producción retórica y la literatura propagandística generada durante estos años marcados por la tensión internacional y la expectación profética: un período convulso y al mismo tiempo decisivo en la construcción simbólica de la Monarquía de los Reyes Católicos.
\end{abstract}

\section{Palabras clave}

Fernando II de Aragón y V de Castilla; Reyes Católicos; propaganda; mesianismo real; Guerras de Italia; Papado; expansión mediterránea.

\begin{abstract}
In the last decade of the fifteenth century the image of Ferdinand the Catholic acquired a European dimension, defined by his relations with the Papacy, his projects of expansion in the Mediterranean, and the dispute with France over the Kingdom of Naples. The present study reconstructs the trajectory of this political icon, which is not always upward, making use of the opinions of chroniclers, the rhetorical production and the propaganda literature that was generated during these years which were marked by international tension and prophetic expectancy: a period of convulsion, and at the same time decisive in the symbolic establishment of the monarchy of the Catholic Kings.
\end{abstract}

\section{Key words}

Ferdinand II of Aragon and V of Castile; Catholic Kings; propaganda; royal messianism; Italian Wars; Papacy; Mediterranean expansion.

* E-mail: afdecordova@unav.es 


\section{Résumé}

$\mathrm{Au}$ cours de la dernière décennie du $X \mathrm{~V}^{\mathrm{e}}$ siècle, l'image de Ferdinand le Catholique acquit une dimension européenne du fait de ses relations avec la Papauté, de ses projets d'expansion méditerranéenne et du conflit avec la France pour le royaume de Naples. Dans ce travail nous prétendons reconstruire la trajectoire - pas toujours ascendante- de cet icône politique à travers les jugements des chroniqueurs, la production rhétorique et la littérature propagandiste de ces années marquées par la tension internationale et l'expectative prophétique: une période agitée et en même temps décisive dans la construction symbolique de la Monarchie des Rois Catholiques.

\section{Mots-clés}

Ferdinand II d'Aragon et V de Castille; Rois Catholiques; propagande; messianisme royal; Guerres d'Italie; Papauté; expansion méditerranéenne.

\section{Introducción ${ }^{1}$}

Desde el descenso de Carlos VIII de Francia a Italia (1494) al fin de la guerra de Nápoles (1504) se extiende un periodo crucial de la historia europea que convirtió la península italiana en terreno de conquista y laboratorio de mutaciones políticas y mentales ${ }^{2}$. Las "guerras de Italia" no se limitaron a una confrontación militar entre la monarquía francesa y la hispánica, sino que expresan una pugna en el ámbito del imaginario político y de lo sacro por el primado simbólico en la Cristiandad occidental ${ }^{3}$. La clausura de la campaña granadina, el hallazgo de nuevas tierras en el Atlántico, y el acceso al pontificado de un valenciano, eran signos elocuentes de una época donde los reinos recién unificados de Aragón y Castilla estaban llamados a desempeñar un papel nada desdeñable en el nuevo orden internacional.

La monarquía hispánica, como la francesa, no fue insensible a estas transformaciones que tuvieron importantes consecuencias en la autocomprensión de su poder y su destino en el escenario europeo ${ }^{4}$. En esta encrucijada de ideales y mensajes propagandísticos se fue tejiendo la imagen de Fernando II de Aragón e Isabel I de Castilla-llamados

Este artículo forma parte del proyecto de investigación Teología política de las monarquías hispanas bajomedievales: un estudio comparativo (HAR2011-30265), aprobado y financiado por el Ministerio de Ciencia e Innovación del Gobierno de España.

2 Algunas contribuciones recientes a esta temática se encuentran en Danielle BoILlet, Marie-Françoise Piéjus, y Denis FACHARD (ed.), Les guerres d'Italie: Histoires, pratiques, representations, París, Université de Paris III Sorbonne Nouvelle, 2002; Christine Shaw (ed.), Italy and the European Powers: The Impact of War, 1500-1530, Leiden, Brill, 2006; Marco Pellegrini, Le guerre d'Italia, 1494-1530, Bolonia, Il mulino, 2009; Michael Mallett, y Christine Shaw, The Italian Wars, 1494-1559: War, State and Society in Early Modern Europe, Harlow, England, Pearson, 2012.

3 Pellegrini, Le guerre d'Italia..., pp. 20 y ss.

4 Sobra la ideología de la "franco-italia" desarrollada en Francia cfr. Jonathan Dumont, Lilia florent. L'imaginaire politique et social à la cour de France durant les premières Guerres d'Italie (1494-1525), París, Honoré Champion, 2013; ID., "Des guerres contre l'anarchie: constructions idéologiques à la cour de France au temps des premières Guerres d'Italie (1494-1525)", en Simone MAZAuric (ed.), Écrire la guerre, écrire la paix. $136^{\circ}$ Congrès national des Sociétés historiques et scientifiques, Perpignan, Éditions du CTHS, 2013, pp. 42-52. 
"Reyes Católicos" desde 1496- al compás de los sucesos internacionales y la producción literaria que generaban 5 . Fue una labor realizada por aquellos intelectuales, eclesiásticos y agentes de diverso tipo que se beneficiaban de los vínculos entre la corte hispana y la Curia de Alejandro VI, el Milán de los Sforza, la Bolonia de los Bentivoglio y el Nápoles Trastámara. Los espacios de comunicación que generaban estos enlaces facilitaron la creación de discursos y mensajes propagandíscos que dieron forma a la imagen de los monarcas en función de las necesidades políticas de la península Italiana. De ahí que sea preciso relacionar esta rica producción con los principales acontecimientos internacionales de la década de 1490: el enfrentamiento con Francia, la alianza con el papado, la pugna por el reino Nápoles y los proyectos de expansión mediterránea. Sin olvidar los eventos internos que tambien condicionaron la percepción de los Reyes Católicos en la medida en que comprometían su proyecto político, como el atentado a Fernando en 1493, los matrimonios de los infantes o la crisis desencadenada por el fallecimiento del heredero en 1497.

Todos estos elementos deben ser ponderados para reconstruir la trayectoria icónica, no siempre regular ni homogénea, de Isabel y Fernando en el último período de su reinado, probablemente el más desconocido. Estas páginas quieren reconstruir las fases de esta evolución como decantación de los ideales de su tiempo, las sintonías ideológicas con las potencias aliadas y, en algunas ocasiones, como resultado de un ejercicio de propaganda originado en determinados centros de poder 6 . Para ello ha sido preciso reunir una gran variedad de fuentes editadas e inéditas, poco conocidas por la historiografía, que desde la cronística, oratoria, lírica y tratadística marcaron los contornos simbólicos e ideológicos de una de las monaquías más poderosas de su tiempo.

\footnotetext{
5 Tratamos esta cuestión en Álvaro Fernández de Córdova Miralles, "Imagen de los Reyes Católicos en la Roma pontificia", En la España Medieval, 28 (2005), pp. 259-354; ID., "Reyes Católicos: mutaciones y permanencias de un paradigma político en la Roma del Renacimiento", en Carlos José HeRnANDo SÁNCHEZ (coord.), Roma y España. Un crisol de la cultura europea en la Edad Moderna, Madrid, Sociedad Estatal para la Acción Cultural Exterior, 2007, pp. 146-154. Una aproximación más detenida a los primeros años del reinado hasta 1492 en "La emergencia de Fernando el Católico en la Curia papal: identidad y propaganda de un príncipe aragonés en el espacio italiano (1469-1492)", en La imagen de Fernando el Católico en la historia, la literatura y el arte (dir. Aurora Egido MarTínez), Institución "Fernando el Católico", CSIC, Zaragoza, 2014, pp. 29-81. Véanse también los trabajos de Carlos José Hernando SÁnchez, "La imagen de Isabel la Católica en la cultura del Renacimiento", en Julio Valdeón Baruque (coord.), Visión del reinado de Isabel la Católica, Valladolid, Ámbito, 2004, pp. 147-194; Devid Paolini, "Los Reyes Católicos e Italia: los humanistas italianos y su relación con España", en Nicasio SALvador Miguel, Cristina Moya García (eds.), La literatura en la época de los Reyes Católicos, Madrid-Frankfurt am Main, Verbuert, 2008, pp. 189-206.

6 Sobre la temática de la imagen regia y su relación con la propaganda se encuentran análisis dispares y a veces complementarios en Ernest GoмвRich, "The art of imposing a pattern on reality", en Journal of the Warburg and Courtauld Institutes, 24 (1961), pp. 307 y ss; Le forme della propaganda politica nel Due e nel Trecento, Roma, Ecole Française de Rome, 1994; Nicole Hochner, Louis XII. Les dérèglements de l'image royal, Seyssel, 2006, pp. 11-32; ID., "Réflexions sur la multiplicité des images royales: incohérance ou quête d'identité?", en Thomas W. Gaehtgens y Nicole Hochner (dirs.), L'image du roi de François I à Louis XIV, París, Editions Maison des Sciences de L'Homme, 2006, pp. 19-32. Para la bibliografía española remitimos a los trabajos citados en La emergencia de Fernando el Católico en la Curia papal..., pp. 30-32.
} 


\section{La pax hispanica en la Roma de Alejandro VI}

\subsection{Gloria coextensiva ante la elección de Alejandro VI}

La elección papal de Alejandro VI el 11 de agosto de 1492 permitió relacionar los éxitos de la monarquía hispánica, principalmente la conquista de Granada, con la nueva Roma gobernada por un papa valenciano. La coincidencia de ambos hechos fue advertida por Michele Ferno en su Historia nova Alexandri VI (Roma, 1493) y manifestada por el patriciado romano en sus expresiones de júbilo por la elección pontificia: Spaña, Spaña, eviva, eviva papa Alessandro romano ${ }^{7}$. Una exaltación patriótica promovida por aquellos curiales "di Spagna" que anunciaban la elección del "Vize canziglieri", y que pudo discurrir por los senderos del profetismo popular que consideraba cumplida en 1492 la profecía sobre la destrucción de los musulmanes [toma de Granada] "quando el buey o vaca [animal heráldico de los Borja] paçiesse çercado de cruzes". Una exaltación que inquietaba a otros, como el poeta Serafino Aquilano, temeroso de que la nave petrina fuera gobernada por "la galera de un catalán" al servicio de los íberos ${ }^{10}$.

Esta simbiosis hispano-romana ha suscitado recientemente la reflexión sobre el nacimiento de una "Roma española" que fue tomando cuerpo en estas fechas hasta convertirse en puntal de la reconstrucción confesional europea ${ }^{11}$. Aunque la Roma de Alejandro VI no era una prolongación de la corte hispana, lo cierto es que asistimos a la elaboración de un discurso pan-ibérico que estrechaba los vínculos ideológicos, políticos y religiosos de ambos centros de poder. Entre los primeros testimonios se hallan dos opúsculos publicados durante la embajada de prestación de obediencia enviada por Isabel y Fernando

\footnotetext{
Sobre los festejos hispanos e italianos por la elección de Alejandro VI cfr. FERnÁndeZ de Córdova, Alejandro VI y los Reyes Católicos. Relaciones político-eclesiásticas (1492-1503), Roma, Edizioni Università della Santa Croce, 2005, pp. 263-274. Las aclamaciones del patriciado romano se recogen en la carta de Francisco de Valencia, Roma 9 octubre 1492; transcrita por Miguel Batllori, La familia de los Borjas, Madrid, Real Academia de la Historia, 1999, pp. 251-254. En este ambiente de exaltación nacional, no es extraño que el poeta Antonio Cammèlli, llamase a Alejandro VI "Tor di Spagna" (toro de España), aludiendo al animal -en realidad un buey- de sus armas; Rodolfo RenIER, I sonetti di Pistoia giusta l'apografo Trivulziano, en Biblioteca di testi inediti o rari, vol. II, Turín, Ermanno Loescher, 1888, p. 314 (soneto 435). 8 Versos del poeta burlesco Antonio Cammèlli, llamado "il Pistoia" (1436-1502); RenIER, I sonetti di Pistoia..., p. 403 (nota aggiunta).

9 Profecía que un pastor jienense veía cumplida en 1492, año en que "se tomó Granada" y "fue criado Papa Alejandro"; véase el epígrafe Armas de Borja, recogido en la colección de noticias atribuidas a un anónimo dominico sevillano de mediados del siglo XVI; Floreto de anécdotas y noticias diversas que recopiló un fraile dominico residente en Sevilla a mediados del siglo XVI, ed. F. J. Sánchez Cantón, en Memorial histórico español, vol. 48, Madrid, 1948, p. 42. Sobre los festejos romanos por la toma de Granada acúdase la bibliografía citada y el estudio que prepara Nicasio SAlvador Miguel, La guerra de Granada (1482-1492). Repercusiones festivas y literarias en Roma.

10 Serafino Aquilano, Rime, ed. Menghini, Bolonia, Romagnoli-Dall'Acqua, 1894, p. 129 (soneto XCI).

11 Véase el análisis centrado en los siglos XVI y XVII de Thomas James Dandelet, La Roma española (1500-1700), Barcelona, Crítica, 2002. Y las consideraciones de Maria Antonietta Visceglia, "Vi è stata una Roma spagnola?", Roma moderna e contemporanea, XI-1/2, 2003, pp. 313-323; ID., Roma papale e Spagna: diplomatici, nobili e religiosi tra due corti, Roma, Bulzoni, 2010.
} 
en el verano de $1493^{12}$ : la Oratio super praestanda solemni obedientia de Bernardino López de Carvajal, desde la posición hispana, y el Commentarius de creatione et coronatione Alexandri VI del auditor romano Girolamo Porcari, desde la perspectiva romana. El discurso de Carvajal, pronunciado el 19 de junio y publicado pocos meses después por Stephan Plannck, describe con tintes mesiánicos la unión de ambos soberanos que encarnan -en sugestiva imagen bíblico-heráldica- la unión del buey de los Borja y el león de los reyes de Castilla, reconciliados por la figura del Niño, imagen de Jesucristo, Señor y Pastor, en la célebre imagen de Isaías (XI, 6) ${ }^{13}$. La alegoría daba alas a un mesianismo hispano donde la autoridad política y la religiosa compartían una singular sintonía para extender el nombre de Cristo en la Indias recién descubiertas ${ }^{14}$.

La oratio de Carvajal subrayaba una nueva era de paz y concordia universales gracias al entendimiento del papa y los reyes tras su desencuentro inicial por ciertas provisiones episcopales. La exaltación de la paz respondía además al objetivo de una embajada que debía deshacer la confederación de Milán, Venecia y el papado, contra Ferrante de Nápoles, ante las peligrosas reivindicaciones de Carlos VIII de Francia sobre el reino partenopeo que había pertenecido a los Anjou. El lujo que adornó la embajada de López de Haro no tenía otro sentido que el de apoyar estas negociaciones en un contexto de indignación "contra las guerras que cundían en Italia entre los cristianos" y la indolencia pontificia por "tender a la disipación de la misma fe" mientras el rey Fernando de Aragón exponía su estado y su vida "en continua pugna con los infieles"15. Un mensaje pacificador que recuperaba la propaganda de la embajada del conde de Tendilla (1486-1487) como fundator Italiae pacis et honoris en un contexto semejante de agresión al reino de Nápoles ${ }^{16}$.

El nuevo discurso nacía de la estabilidad que dominaba entonces el Mediterráneo, y permitía augurar una nueva paz augusta de tintes religiosos donde el angel de Dios sustituyese la espada por la cruz, pues "Il Turco dorme e riposa il Soldano, / la Spagna

\footnotetext{
12 Maria Grazia Blasio, "Retorica della scena: l'elezione di Alessandro VI nel resoconto di Michele Ferno", en Davide Canfora, Maria Chiabò, Mauro de Nichilo (dirs.), Principato ecclesiastico e riuso dei classici. Gli umanisti e Alessandro VI (Bari-Monte Sant'Angelo, 22-24 maggi 00), Roma, Roma nel Rinascimento, 2002, pp. 19-36.

13 Bernardino López de CARVAJAL, Oratio super praestanda solemni obedientia sanctissimo domino nostro Alexandro papae VI ex parte christianissimorum dominorumque Ferdinandi et Helisabeth, regis et reginae Hispaniae, habita Romae in consistorio publico per R. Patrem dominum Bernardinum Carvajal episcopum carthaginensem, ed. Eucharius Silber, Roma, 1493; Biblioteca Apostólica Vaticana (Ciudad del Vaticano) [a partir de ahora BAV], Inc. IV. 566.

${ }_{14}$ Otros usos providencialistas de la imagen de Isaías en la propaganda hispana del momento en José Guadalajara, Las profecías del Anticristo en la Edad Media, Madrid, Gredos, 1996, pp. 171 y ss.

15 Stefano Infessura también destaca la entrada del embajador "cum magno comitatu episcoporum et curialium, et factus fuit ei honor magnus"; Infessura, Diario della città di Roma, ed. de O. Tomassini, Fonti per la Storia d'Italia, vol. V, Roma, Istituto storico italiano, 1880, pp. 287-288.

16 Sobre esta embajada véase la bibliografía citada en nuestros trabajos, a la que hay que añadir la reciente investigación de María Cristina Hernández Castelló, Don Íñigo López de Mendoza, II conde de Tendilla, y las Artes: ¿entre España e Italia?, Valladolid, Universidad de Valladolid 2013.
} 
siede e la Granata giace"17. Mientras tanto, se anunciaba la misma idea en el otro océano, el Atlántico, donde el descubrimiento de nuevas tierras arrojaba una luz inédita sobre el rey Fernando que abandonaba su imagen guerrera por un nuevo paradigma civilizador y evangelizador que ampliaba los confines del orbe cristiano, como difundía el florentino Giuliano Dati en su poemetto publicado en junio, con alabanzas al monarca -“cristianissimo rege infra' cristiani"- que de vencedor de los moros se ha convertido en unificador de reinos y propagador de la fe "senza guerra"18. Este optimismo conectaba además con la idea de que se tomara contacto con los pueblos evangelizados por los apóstoles de Oriente -San Bartolomé y Santo Tomás-, colmando un vacío de la historia evangélica que convertía al rey en el "nuevo apóstol" que llevaría a término el mandato de Cristo de predicar a todas las gentes ${ }^{19}$.

A los versos en romance de Dati se adjuntó la traducción latina de la carta de Colón a Gabriel Sánchez (14.III.1493), que legitimaba la posesión de las tierras descubiertas. El impreso editado por Stephanus Planck y Eucharius Silber finalizaba con el epigrama Ad invictissimum Regem Hispaniarum de Ludovico Corbaria -obispo de Montepeloso (Basilicata) y posible ciudadano barcelonés ${ }^{20}$ - que celebra la proeza del "Betico magno"

17 Son los versos del Pistoia: "Ecco tornato il tempo di Ottaviano, / che '1 mondo bilicò sopra la pace. / Christo rinasca pur quando gli piace, / che '1 Mor tiene chiuso il gran tempio di Jano. // Il Turco dorme e riposa il Soldano, / la Spagna siede e la Granata giace. / Il tuo Angelo vòl, ch'era sì audace, la croce in petto, e non più spada in mano"; Renier, I sonetti di Pistoia..., p. 283.

18 La lettera dell isole nuevamente trovate se publicó un mes después a la edición de la carta colombina a Luis de Santángel, convirtiéndose en uno de los primeros best-sellers de las prensas europeas, con no menos de once ediciones en 1493 en cinco países distintos, a las que se añadieron seis ediciones más entre 1494 y 1497; véase nuestro comentario en Fernández de Córdova, Imagen de los Reyes Católicos..., pp. 312-314; Isabel La Católica: la magnificencia de un reinado: quinto centenario de Isabel la Católica 1504-2004, Madrid, Sociedad Estatal de Conmemoraciones Culturales, pp. 359-360; Clara CAmplani, "L'America in Italia nel secolo XV', en ID., y Patrizia Spinato Bruschi (ed.), Dal Mediterraneo: l'America, Roma, Bulzoni, 2006, pp. 25-40.

19 Louis-André Vigneras, "Saint Thomas, Apostle of America", The Hispanic American Historical Review, 57 (1977), pp. 82-90; Juana Mary Arcelus Ulibarrena, "Escatología y conversión al cristianismo en Cristóbal Colón y los primeros evangelizadores del Nuevo Mundo", en Joaquín Marco ReviLla (coord.), Actas del XXIX congreso del Instituto Internacional de Literatura Iberoamericana, Barcelona 15-19 de junio de 1992, vol. 1, Barcelona, PPU, 1994, pp. 261-272; Demetrio RAMOs, "La creencia en la predicación de un apóstol en Indias", en ID., Genocidio y conquista: viejos mitos que siguen en pie, Madrid, Real Academia de la Historia, 1998.

20 Un detallado análisis de la manipulación de la carta colombina para respaldar los derechos de Isabel y Fernando a las nuevas tierras en Demetrio Ramos, La primera noticia de América, Valladolid, Casa-Museo de Colón, 1986, pp. 28-67. No hay que olvidar los precedentes portugueses de este tipo de propaganda desarrollada por Vasco Fernandes de Lucena en su discurso de ante Inocencio VIII en 1485 o el de Fernando de Almeida ante Alejandro VI, editado en abril de 1493 en los mismos meses en que se estaban tramitando las bulas españolas; cfr. Luís de MATos, L'expansion portugaise dans la litterature latine de la Renaissance, Lisboa, Gulbenkian, 1991, pp. 157-185; Maria José Pimenta Ferro Tavares, “A construção da imagem do poder do rei”, en María Isabel del VAL VAldivieso, y Pascual Martínez Sopena (coord.), Castilla y el mundo feudal: homenaje al profesor Julio Valdeón, vol. 2, Valladolid, Junta de Castilla y León, 2009, pp. 423-441. Sobre la compleja gestión de las bulas, especialmente la Dudum siquidem y la Inter caetera II, cfr. Fernández de Córdova, Alejandro VI y los Reyes Católicos..., pp. 478-497. 
al plantar sus enseñas en Oriente y reducir así los límites del Orbe ${ }^{21}$. Una compilación tan variada debió realizarse gracias a la coordinación de un equipo italo-aragonés que contó con el editor siciliano Giovanni Filippo de Lignamine, "domestico familiare" de Fernando y responsable de la publicación romana mientras se gestionaban las bulas del descubrimiento en la Curia papal. Como sucedió con las victorias granadinas, la Ciudad Eterna fue el principal centro difusor de la propaganda indiana, aportando un material que fue copiado en París, Amberes, Leipzig, Basilea, Pavía y Florencia, gracias a la acción coordinada de los impresores alemanes y los agentes en Italia ${ }^{22}$. El latín facilitó su divulgación a través de las potencias de la Liga Santa -Milán, Venecia, Imperio, ducado de Borgoña ${ }^{23}$ - difundiendo el poder marítimo de los monarcas y su contribución a la dilatatio christianitas según una nueva concepción "territorializada" de la cristiandad que dotaba de una nueva universalidad al paradigma de integración ibérica ${ }^{24}$. Ya no se trataba de recuperar antiguos espacios, como en la guerra de Granada, sino de incorporar nuevas tierras y nuevos pueblos "a nuestra santa fe", de manera que "no solamente la España, mas todos los cristianos ternán aquí refrigerio y ganancia", como escribía Colón en su carta triunfalista de 1493.

La primera información de la empresa indiana se extendió en la Italia centro-septentrional, especialmente en Génova, Milán y Florencia, gracias a la correspondencia de mercaderes y diplomáticos como el genovés Annibale De Zennaro (9.III.1493) o el mantuano Giacomo Trotti (21.IV.1493) que informaron desde Milán reproduciendo el tono exaltado de la carta colombiana ${ }^{25}$. Tales noticias originadas probablemente en la corte hispana, exageraban el tamaño y riquezas de las islas, describiendo el hallazgo como uno de los principales eventos del año ${ }^{26}$. En la carta de Lucca Fancelli enviada al marqués de Mantua desde Florencia, se hablaba de las cinco islas descubiertas por

21 La traducción en Martín Fernández de Navarrete, Coleccion de los Viagesy descubrimentos que hicieron por mar los españoles, Madrid, 1825, p. 197. Sobre la identidad de Corbaria cfr. Francesc Albardaner, “Qui fou R. L. de Corbaria, episcopi Montispalusii?", Butlleti Centre d'Estudis Colombins 53 (2010), p. 6. 22 Gian Luigi Beccaria, "Tra Italia Spagna e Nuovo Mondo nell'eta delle scoperte: viaggi di parole", Lettere Italiane, 37 (1935), pp. 177-203.

23 Renate PIEPER, “Anno 1503, la incorporación de los nuevos territorios americanos en el imaginario europeo o por qué América no se llamó ni Coelha ni Colombia”, en José Miguel Delgado Barrado, Ludolf Pelizaeus, y María Cristina Torales PAcheco (eds.), Las ciudades en las fases transitorias del mundo hispánico a los Estados nación: América y Europa (siglos XVI-XX), Iberoamericana-Vervuert, Madrid-Frankfurt, 2014, pp. 48-51.

24 Álvaro FERNÁNDEZ DE CÓRDOVA Miralles, "La política europea de Fernando Hispaniae rex. Del despliegue diplomático a la integración atlántico-mediterránea (1474-1516)", en M. Carmen Morte García, y José Ángel Sesma Muñoz (coord.), Fernando II de Aragón. El rey que imaginó España y la abrió a Europa, Zaragoza, Gobierno de Aragón, 2015, pp. 63-79.

25 Véase la excelente compilación documental de BERCHET, Fonti italiane per la storia della scoperta del Nuovo mondo, vols. I-II, Roma, Ministero della pubblica istruzione, 1892-93. Y los estudios de Rosario Romeo, Le scoperte americane nella concienza italiana Cinquecento, Roma-Bari, Laterza, 1989; AIRALDI, Gabriella, y Formisano, Luciano, La scoperta nelle relazioni sincrone degli Italiani, Roma, Istituto Paligrafico e Zecca dell Stato, 1996; Geoffrey Symcox, y Luciano Formisano (eds.), Italian reports on America, 1493-1522: accounts by contemporary observers, Turnhout, Brepols, 2002, pp. 8-16 y 27-27-30.

26 Véase la carta de Francesco Marchesi y Giovanni Antonio Grimaldi al gobierno genovés en 1493; Ibidem, p. 73. 
el rey de España, "una de ellas tan grande como Italia" (22.IV.1493). Más pragmáticos se mostraron los servidores del Francesco Gonzaga instalados en Cádiz, al describir las riquezas naturales de los nuevos territorios, las cantidades de oro o los doce indígenas entregados al rey ${ }^{27}$. Finalmente contamos con los informes de los embajadores venecianos enviados desde Barcelona, y otros intelectuales como Pedro Mártir de Anglería que escribía a sus amistades romanas y milanesas desde la corte ofreciendo su testimonio imbuido de clasicismo y de un novedoso sentido crítico hacia los modelos antiguos ${ }^{28}$.

Otros comunicadores fueron algunos comerciantes toscanos establecidos en la península Ibérica, como el florentino Simone Verde ${ }^{29}$, o los sieneses que en 1493 informaron a su gobierno de las nuevas islas halladas más allá de las columnas de Hércules, y las "molte Carovelle" que el rey de España pensaba enviar con suministros para instruir a las poblaciones autóctonas, usando como intérpretes a los treinta indígenas formados en su corte ${ }^{30}$. La descripción de los indios, incluyendo los esclavizados por Colón, constituye el tema de los relatos de su segundo viaje transmitidos por mercaderes establecidos en Sevilla y Cádiz (19. III y 19 IV. 1494) ${ }^{31}$. Alguno de ellos debió ser enviado a Italia, como sucedió con algunos vencidos en la campaña de Málaga (1487) o aquel "rey negro" de Canarias entregado por los reyes al gobierno veneciano y remitido a la corte de Mantua en $1497^{32}$. Mientras tanto, embajadores como Juan Claver informaron de los viajes colombinos a través de relatos entregados a Ludovico Sforza-duque de Milán- y a Hércules de Este, señor de Ferrara ${ }^{33}$. No se trataba sólo de saciar la curiosidad de estos príncipes, sino de facilitar el entendimiento diplomático y ganar la confianza de las potencias en el poder hispano ante la amenaza francesa que se cernía sobre la península Italiana.

27 Julia Mary Cartwright Ady, Isabella D'Este, Marchioness of Mantua, 1474-1539: A Study of the Renaissance, vol. I, Londres, E. P. Dutton y J. Murray, 1903, pp. 94-97.

28 Domenico Malpiero, "Annali veneti dall'anno 1457 al 1500", Archivio storico italiano, 7 (1843), pp. 313-314. Los informes mantuanos en Berchet, Fonti italiane..., vol. I, pp. 165-169. Miguel Ángel Ladero Quesada, "La descripción del Nuevo Mundo en la primera mitad del siglo XVI: Pedro Mártir de Anglería y Gonzalo Fernández de Oviedo", Estudios de historia de España, 12-2 (2010), pp. 313-333.

29 Véanse sus cartas de 1494 y 1498 reproducidas por Henry HaRris, Christophe Colomb devant l'histoire, Paris, H. Welter, 1892, pp. 68-76.

30 Allegretto Allegretti, Diari sanesi, en L. A. Muratori (ed.), Rerum Italicarum Scriptores, vol. XXIII, Milán, 1733, p. 827. El cronista florentino Piero di Marco Parenti también consigna el descubrimiento por "el Re di Spagna" de nuevas y grandes islas de las que no se tenía ninguna noticia "copiose d'oro principalmente, di cennamo, cotone e altre cose", donde los hombres iban semidesnudos y adoraban a divinidades naturales; Piero di Marco Parenti, Storia fiorentina, vol. I, Florencia, L.S. Olschki, 2005, p. 45.

31 Symcox, y Formisano (eds.), Italian reports..., pp. 43-45.

32 Malpiero, Annali veneti..., p. 487; Berchet, Fonti italiane..., pp. 41-42; Symcox, y Formisano (eds.), Italian reports..., pp. 48-49.

33 La carta de Claver en José Enrique LóPEZ de COCA CASTAÑER, "Publicidad en torno al tercer viaje colombino: fragmento de una carta de Juan Claver a Ludovico el Moro (enero de 1499)", en Alberto Boscolo Y BiBiano (dir.), La presenza italiana in Andalusia nel Basso Medioevo, Bolonia, Cappelli, 1986, pp. 233-242. Sobre el libreto enviado al duque de Ferrara a través del embajador Antonio Costabili, véase la carta de éste datada en Milán, 12 febrero 1496; Symcox, y Formisano (eds.), Italian reports..., p. 46. Y el análisis de Rosario Romeo, Le scoperte americane nella concienza italiana Cinquecento, Roma-Bari, Laterza, 1989. 
En este campo, el nuevo icono fernandino heredaba los perfiles evangelizadores de Enrique el Navegante ${ }^{34}$ y eclipsaba a su esposa Isabel tanto en el texto de Giuliano Dati como en los grabados de la carta colombina, aunque el papa la incluyera a conciencia en las bulas indianas ${ }^{35}$. Un año después el rey conservaba este monopolio mediático en la traducción latina de la epístola que Sebastian Brant incluyó en la edición basiliense de la Historia Baetica (1494) junto al himno In beticum triumphum congratulatio, exaltando el hallazgo de unas tierras que corregían los errores geográficos de Plinio y Ptolomeo ${ }^{36}$. El mismo año en que el médico y humanista Niccolò Scillacio desarrolló el mito de la edad dorada en su De insulis meridiani atque indici maris nuper inventi dedicado en 1494 a Alfonso de la Caballería, vicecanciller del rey Católico ${ }^{37}$. La respuesta pontificia a estos mensajes de concordia se halla en el Commentarius de creatione et coronatione Alexandri VI que el noble romano Girolamo Porcari ( $† 1503)$ dedicó a Isabel y Fernando, imprimiéndose en Roma el 18 septiembre de 1493. Este auditor próximo al papa, interpreta su reciente elección como una coincidencia providencial en la que los monarcas aportaban a Roma, no sólo la gloria de sus triunfos granadinos, "sed ipsam victoriam"38. En su deliberada búsqueda de vínculos simbólicos, sociales e históricos entre España y la Ciudad Eterna, el autor invita a Fernando a que visite la ciudad en un claro gesto de fusión del nuevo imperio cristiano con el de la antigua

\footnotetext{
34 Descobrimentos Portugueses. Documentos para a sua história publicados e prefaciados por João Martins da Silva Marques, vol. I, pp. 1147-1160, Lisboa, Instituto para a Alta Cultura, 1988. Recientemente Massimo Miglio, "Continuità e fratture nei rapporti tra Papato e Spagna nel Quattrocento", en En los umbrales de España: la incorporación del Reino de Navarra a la monarquía hispana (XXXVIII Semana de estudios medievales, Estella, 18-22 de julio del 2011), Pamplona, Gobierno de Navarra, Departamento de Cultura, Turismo y Relaciones Institucionales, 2012, pp. 291-294.

35 Protagonismo que debe ponerse en relación con la entrega de las Indias a ambos monarcas como "Reyes de Castilla y León", y no de Aragón, pues la base jurídica de la donación eran los derechos que se derivaban para Castilla de las paces de Alcáçovas; cfr. Demetrio RAmos, "La aparente exclusión de los aragoneses de las Indias: Una medida de alta política de Fernando el Católico", en ID., Genocidio y conquista..., pp. 171-173.

36 Los versos se recogen en Henry HARrISSE, Bibliotheca americana vetustissima: a description of works relating to America published between the years 1492 and 1551: additions, ed. de Carlos Sanz, Madrid, Suárez, 1958, pp. 6-7 (n. 5).

37 Nicolò ScILlatio, Sulle isole meridionali e del mare indico nuevamente trovate, ed. de Maria Grazia Scelfo Micci, Roma, Bulzoni, 1990. Y las puntualizaciones de Giovanni Battista DE CESARE, "Il secondo viaggio colombiano visto da Pavia: Nicolò Scillacio", en Serena ogni montagna. Studi di Ispanisti Amici offerti a Beppe Tavani, G. Bellini, y D. Ferro (eds.), Roma, Bulzoni, 1997, pp. 139-147; Camplani, L'America in Italia..., pp. 36-37.

38 Hieronimus Porci, Commentarius de creatione et coronatione Alexandri VI, ed. Eucharius Silber, Roma 1493; en IERS 1396; BAV, Inc. VI. 8; cfr. Fernández de CóRdova, Alejandro VI y los Reyes Católicos..., pp. 119, 169, 259-260 y 272-273; Manuel Vaquero PiñeIro, "De los Reyes Católicos a Carlos V: el cambio dinástico visto desde la Corte de Roma", en Alfredo Alvar Ezquerra, Jaime Contreras Contreras, y José Ignacio Ruzz Rodríguez (eds.), Política y cultura, en la época moderna: cambios dinásticos, milenarismos, mesianismos y utopías, Alcalá de Henares, Universidad de Alcalá, 2004, p. 139. Ruiz García ha identificado otra obra suya, In Turco Porcia declamatio, entre los libros de la reina; Elisa Ruiz García, Los libros de Isabel la Católica. Arqueología de un patrimonio escrito, Madrid, Instituto de Historia del Libro y de la Lectura, 2004, p. 622.
} 
Roma, apostando igualmente por una fértil colaboración de ambos poderes gracias a la natio hispana instalada en la Urbe bajo la protección del papa ${ }^{39}$.

Trufado de ideales cruzadistas, Porcari vincula España y Roma con Jerusalén, cada vez más cercana gracias a la expansión de Isabel y Fernando hacia Oriente y, también hacia Occidente, pues ya se difunden desde Cádiz los admirables descubrimientos ("milibilia tua"). Conquistada Granada y sometida África bajo tributo, Porcari anuncia la globalización de un espacio oceánico - de mar a mar ("a mari usque ad mare")- que los reyes dominarán bajo la guía de Cristo ("Christo duce")" el Salmo 122: "Dabitque illis dominus possessionem terminis terrae".

\subsection{Un rey salvado en una Europa convulsa}

En el ambiente de entusiasmo hispánico que se respiraba en Roma es lógico que la noticia del atentado sufrido por el rey el 7 de diciembre suscitara consternación y se recogiera en las crónicas italianas ${ }^{41}$. Interesado en suavizar las iniciales tensiones con la corte, Alejandro VI impulsó la celebración de una Misa de acción de gracias tras la recuperación del rey y la publicación de carteles alusivos ${ }^{42}$. El acontecimiento también generó algunas composiciones literarias: la tragicomedia Fernandus Servatus que Marcelino Verardi dedicó al cardenal Mendoza, el drama Pluto furens de Pedro Mártir de Anglería enderezado al propio Alejandro VI y el poema latino de Ugolino Verino.

Antes de su publicación, la obra de Verardi fue escenificada el 27 de marzo de 1493 en el palacio del cardenal Riario, ante el papa, el colegio cardenalicio y otros dignatarios ${ }^{43}$.

39 Porcil, Commentarius de creatione..., f. 2 r.

40 Ibidem, ff. 9 y 19.

41 Un interesante análisis del acontecimiento en el contexto de la Corona de Aragón en José Ángel SeSMA MuÑoz, Los Idus de Diciembre de Fernando II. El atentado del Rey de Aragón en Barcelona, Zaragoza, Institución Fernando el Católico, 2006.

42 Fernández de Córdova, Alejandro VI y los Reyes Católicos..., pp. 170-173. En Nápoles se recoge la noticia en Notar Giacomo, Cronica di Napoli, ed. de P. Garzilli, Nápoles, Stamperia Reale, 1980 (1 $1^{\text {a }}$ ed 1845), p. 177. Posteriormente Maquiavelo se hará eco del atentado para mostrar la accesibilidad del rey: "uno spagnuolo povero ed abietto dette una coltellata in su el collo al re Ferrando, re di Spagna: non fu la ferita mortale, ma per questo si vide che colui ebbe animo e commodittà a farlo"; en Niccolò Maquiavello Discorsi, cap. 6, n. 3; en ID., Opere, vol. I, Turín, Einaudi-Gallimard, 1999. El florentino Piero di Marco Parenti, también consigna el hecho como "cosa grande e maravigliosa", ponderando el atentado a la salida del Consejo, por un loco que le hirió en el cuello y fue ajusticiado por descuartizamiento; PArenti, Storia fiorentina..., vol. I, p. 42.

43 Maria Teresa Graziosi, "Tradizione e realtà nel Fernandus Servatus", en Atti e Memorie dell'Accademia letteraria italiana dell'Arcadia, 6-2 (1973-76), pp. 55-71; José Luis Gotor LóPez, "Il carme De casu regis di Pietro Martire d'Anghiera e la tragicomedia Fernandus seruatus di Marcellino Verardi", en La rinascita della tragedia nell'Italia dell'Umanesimo, Viterbo, Centro studi sul Teatro medioevale e rinascimentale, 1976, pp. 159-184; Ursula Hecht, Der 'Pluto furens' des Petrus Martyr Anglerius. Dichtung als Dokumentation, Frankfurt am Main, 1992; Davide CANFORA, "Il carme Supra casum Hispani regis di Pietro Martire d'Anghiera dedicato al pontefice Alessandro VI", en Id., Maria Chiabò, y Mauro De Nichilo (dirs.), Principato ecclesiastico..., pp. 275-84; María Dolores Rincón GonZÁlez, "Discite nunc igitur, Reges, aeterna mereri nomina: una interpretación del atentado de Barcelona de 1492", en De orbis Hispani linguis litteris historia 
Con poderosas reminiscencias senequistas, Verardi describe a un Fernando "preservado" por la Providencia de una conspiración perpetrada por los poderes infernales contra la Cristiandad. Incapaz de dominar el alma del rey, el maligno intenta acabar con su vida en un atentado que Dios permite para que resplandezca la virtud del monarca aragonés, convirtiéndose en icono martirial del "rey sufriente" que al expiar una culpa inmerecida se identifica con el mismo Jesucristo ${ }^{44}$. De esta manera el autor lograba convertir un aparente signo de debilidad, la herida del rey, en una demostración de su virtud, resaltando su condición de líder de la Cristiandad en la lucha contra las fuerzas del mal. Sin embargo, Verardi no se contenta con la exposición de la historia pues además describe la atención con que el papa y los cardenales asistieron a la representación ("tanto autem fauore et attentione"), así como el impacto que les causó, mostrándose tan impresionados de la virtud del monarca ("sola fama uirtutun Fernandi Regis") que desearon tener más noticias de él ${ }^{45}$.

Pedro Mártir de Anglería empleó un argumento casi idéntico en su drama Pluto furens probablemente entregado a Diego López de Haro para hacérselo llegar al papa. Al igual que Verardi, el milanés interpreta el intento de magnicidio como una conspiración diabólica para destruir la unidad política lograda por Fernando ${ }^{46}$. Si la obra se incorporó a la embajada de prestación de obediencia pudo reforzar la identificación del rey aragonés con la dinastía napolitana asumiendo un papel de víctima inocente ante la invasión francesa. En tal caso el Pluto furens se identificaría con un agresivo Carlos VIII dispuesto a descargar el crimen de la guerra sobre unos príncipes que no serían abandonados por la Providencia divina.

En el caso de los 60 versos compuestos por Ugolino Verino, el agresor es el Islam, que perpetra el atentado para frenar la inminente campaña del rey contra el norte de África. Se reactivaba así la propaganda cruzadista en un nuevo contexto, el africano, aunque su desarrollo tenga lugar en los años centrales de la década de 1490 en que se retoman los proyectos militares en el Mediterráneo occidental. La Gratulatio christianorum de incolumitate Ferdinandi regis Hispaniarum ab insultu fanatici parricidae, constituye una acción de gracias por la salvación del rey y una exhortación a los demás príncipes cristianos a unirse a la plegaria. Como sucediera en su obra

moribus: Festschrift für Dietrich Briesemeister zum 60. Geburtstag, vol. 1, Frankfurt, 1994, pp. 567-576; Hartmut Beyer, "Carlo and Marcellino Verardi's Fernandus servatus and the Poem Supra casum Hispani regis by Petrus Martyr: Drama and Diplomacy in Papal Rome under Alexander VI", en Jan Bloemendal, Peter G. F. Eversmann, y Elsa Strietman (ed.), Drama, Performance and Debate. Theatre and Public Opinion in the Early Modern Period, Leiden, Brill, 2012, pp. 35-56; Gianni Antonio Palumbo, "Una santa alleanza in difesa della fede, il Fernandus servatus di Marcellino Verardi", en Luisa Secchi TARugi (ed.), Roma pagana e Roma cristiana nel Rinascimento. Atti del XXIV Convegno Internazionale (Chianciano Terme-Pienza 19-21 luglio 2012), Florencia, Cesati, 2014, pp. 283-290.

44 Dios permite que el piadoso rey sufra una herida mortal para mostrar la virtud en la desgracia; idea de Séneca que Verardi pone en labios del apóstol Santiago para reconfortar a la reina.

45 Beyer, Carlo and Marcellino Verardi's Fernandus servatus..., p. 47.

46 Ibidem, p. 49. 
granadina, Verino no olvida a Isabel, copartícipe de la salvación de su marido: ellos son los "santos reges" que hacen temblar a África y las ciudades de Siria ${ }^{47}$.

\subsection{La sombra de Isabel y la emergencia del heredero}

La reina no permaneció ajena a los nuevos rumbos de la propaganda hispana. Su perfil enérgico, culto y religioso esbozado durante la guerra de Granada adquirió en la década de 1490 una tonalidad política especialmente visible en las cortes septentrionales de la península italiana. Coadyuvó a ello la apertura diplomática a Génova, Milán y Venecia para frenar la invasión francesa, aunque las primeras manifestaciones puedan detectarse en 1492 con la publicación del Opusculum de conceptione Virginis (Milán, 1492), traducción latina de la obra en castellano que dedicó a Isabel el milanés Pietro del Monte. La obra forma parte del mecenazgo religioso iniciado por el Epodon de Geraldini y que ahora trata un tema sensible en la corte de la reina, tanto en sus aspectos teológicos como en las asociaciones propagandísticas de Isabel con la Virgen María ${ }^{48}$.

En este plano erudito se sitúa la correspondencia personal con la humanista Casandra Fedele (1465-1558), intelectual de la Universidad de Padua célebre por su sabiduría y su piedad ${ }^{49}$. La reina intentó atraerla a su corte para escribir su biografía ajustándola a los valores con los que gobierna, en busca quizá de una obra equivalente a los Fasti que Antonio Geraldini había dedicado a su esposo. Las cinco cartas conservadas en el período 1487-1497 muestran el arraigo de la imagen cruzadista de la soberana, descrita

\footnotetext{
47 "Christicolae interea tanto pro munere grates / Innumeras animo mundo referamus ovantes, / Solvamus pia vota deo; nil rege timendum est / Tam claro incolumi, cuius tremit Africa nomen / Formidantque urbes Syriae, ne Martia victor / Agmina Ferrandus Solimorum ducat in arcem" (vv. 65-70); Gratulatio christianorum de incolumitate Ferdinandi regis Hispaniarum ab insultu fanatici parricidae, Biblioteca Nacional de España (Madrid) [BNE], Ms. 5821, ff. 45r-47r, especialmente 47r.

48 Ronald E. Surtz, "The Reciprocal Construction of Isabelline Book Patronage", en Barbara F. Weissberger (ed.), Queen Isabel I of Castile: Power, Patronage, Persona, Woodbridge, Boydell and Brewer, 2008, pp. 56-57. Sobre la devoción isabelina por la doctrina de la Inmaculada Concepción, en su dimensión pública y privada, cfr. John EDwards, Isabel la Católica: poder y fama, Madrid, Marcial Pons, 2004, pp. 109-111. A estos datos cabe añadir obras poco conocidas como el Tratado en que se demuestra como la intencion de los que compiten sobre la materia de la Concepcion y Santificacion de la Virgen Maria Nuestra Señora es santa y buena, dedicado a Isabel y Fernando; Biblioteca de Catalunya (Barcelona), Ms. 2018. Tratamos algunas de estas cuestiones en Álvaro Fernández de CóRdova, "La fe de una reina: Isabel la Católica", en Pablo Pérez (dir.), Personajes de fe que hicieron historia, Madrid, Rialp, 2014, pp. 15-45.

49 Ambrogio Levatı, Dizionario biografico cronologico delle donne illustri, vol. I, Milán, Per Nicolò Bettoni, 1821, p. 146; Franco Pignatti, "Fedele (Fedeli), Cassandra", en Dizionario Biografico degli Italiani, vol. 45, 1995, Roma, Treccani, pp. 566-568. La correspondencia de esta célebre intelectual de la Universidad de Padua ha sido rescata por Maria Isabel Segarra AÑón, "Epístolas de una humanista a una reina: Cassandra Fedele e Isabel la Católica", en José María Maestre Maestre, Luis Charlo Brea, Joaquín Pascual BAREA (coord.), Humanismo y pervivencia del mundo clásico: Homenaje al profesor Luis Gil, vol. II, Cádiz, Ayuntamiento de Alcañiz, Universidad de Cádiz, 1997, pp. 1197-1204; ID., "Bajo la sombra de tus alas. Isabel la Católica y Cassandra Fedele", Miscelánea Comillas, 69-134 (2011), pp. 275-292. Y el comentario de Fernando Gómez Redondo, Historia de la prosa de los Reyes Católicos: el umbral del renacimiento, vol. I, Madrid, Cátedra, 2012, pp. 662-663.
} 
por Cassandra como virgo bellatrix, empeñada en defender a los cristianos y expulsar a los infieles, extendiendo el elogio a su iustitia in administratione imperii. Por su parte, Isabel expresa en su única epístola conservada su interés por el reconocimiento del ingenio femenino que antaño sólo obtuvieron las amazonas y exige una adaptación a los tiempos. Cassandra se mostró favorable a su traslado a la corte hispana, reciendo el apoyo del poeta latino Augurelli y el caballero Girolamo Leone, mediador en sus relaciones con la reina. Sin embargo la República se opuso, quizá por el enfriamiento de las relaciones con los Reyes Católicos a raíz de las treguas firmadas con Carlos VIII en 1498 de espaldas a los miembros de la Liga Santa.

La obra más interesante de la propaganda isabelina tal vez sea el Elogio di Isabella que compuso Sabatino degli Arienti (c.1443-1510) hacia 1493 en la corte boloñesa de Giovanni II Bentivoglio, particularmente receptiva a las profecías fernandinas ${ }^{50} \mathrm{y}$ a los triunfos españoles ${ }^{51}$. El autor usa el modelo del De claris mulieribus de Boccaccio, para componer un panegírico bajo las coordenadas antropológicas del Humanismo, donde la reina supera a las heroínas clásicas por conservar su identidad femenina en el ejercicio de la fortaleza, y aventaja a las mártires cristianas por su extraordinaria capacidad de gobierno $^{52}$. Sus dotes políticas y su identidad cristiana son las piedras angulares de este icono, caracterizado por la castidad matrimonial, la honestidad personal y una actividad política modélica para las mujeres con funciones públicas. Isabel es espejo del perfecto gobernante que adquiere dimensiones europeas gracias a los recientes matrimonios de su progenie. Aunque el Elogio di Isabella no llegara a imprimirse, su composición refleja un estado de opinión que años después permitiría a Cherubino Ghirardaci exaltar a la soberana castellana como "religiosissima regina" [...] "donna di gran prudenza et religione et di una maschia generosità" 53 .

\footnotetext{
50 Véase la carta, datada entre 1486 y 1490, de un dominico catalán residente en Bolonia a un hermano suyo de la misma orden residente en Martorell, transcrita junto a una profecía latina con la nota: "Aquesto uno signo e stato a la magestade de rey en Ferando, ell qualle esta visto per lo quevellari que sono supra le pecore e qu'o visto supra la montanya de Santo Angelo esta fato"; Biblioteca de la Universitat de Barcelona (Barcelona), Ms. 588; cfr. Eulàlia DuRAN (dir.), Repertori de manuscrits catalans (1474-1620), vol. II/1, Barcelona, Universitat de Barcelona, Institut d'Estudis Catalans, 2003, pp. 166-167.

51 El propio Sabatino recuerda en su obra el paso por Bolonia de Íñigo López de Mendoza en 1486 o la presencia estudiantil hispana en el Alma mater Studiorum; cfr. Fernández de Córdova, Alejandro VI y los Reyes Católicos..., pp. 157-159; especialmente Stephen Kolsky, The Ghost of Boccaccio: writings on famous women in Renaissance Italy, Turnhout, Brepols, 2005, pp. 99-109.

52 Para el cortesano boloñés, Isabel ha superado a Hysicratea, reina del Ponto que se disfraza de varón para poder seguir a su marido, pues la soberana castellana no renuncia a su apariencia femenina y, aunque apoye la campaña granadina liderada por Fernando, no se implica en el combate como las Amazonas.

53 Se trata de su Historia di Bologna finalizada en 1586 y realizada con "tutte le scritture degli Archivi de' principali Monasteri et molte Croniche delle più gravi, che per la città vanno d'intorno, oltre i due Registri novo et vecchio; son buona parte delle più antiche scritture della Camera degli Atti, sì come altri Autori gravi et fideli, che delle cose di Bologna hanno scritto"; Cherubino GhiRARDacci, Storia di Bologna, ed. de. A. Sorbelli, Rerum Italicarum Scriptores, vol. XXXIII, vol. I, Città di Castello, Lapi, 1915, p. 265; cfr. Umberto Mazzone, "Ghirardacci, Cherubino", Dizionario Biografico degli Italiani, vol. 53, Roma, Treccani, 2000, pp. 789-792.
} 
Sabatino tampoco olvida a Fernando que lleva la dirección de la guerra de Granada, pero resulta más interesante su atención por las implicaciones dinásticas del regio matrimonio ${ }^{54}$. Con ello se anuncia un nuevo tema propagandístico que empezaba a adquirir particular actualidad: la figura de los infantes, especialmente el príncipe heredero Juan. Su llegada a la edad adulta y la concertación de los matrimonios de las infantas con los Habsburgo y los Tudor, ofrecía una ocasión privilegiada para elaborar una apología dinástica que ponderara la seguridad sucesoria garantizada por los enlaces y la proyección internacional de la casa real hispánica. Antes de que los poetas áulicos desarrollaran las primeras crónicas rimadas dedicadas a los infantes, el tema despuntaba ya en los panegíricos reales como el impulsado por Gonzalo Chacón en torno a 1494-1495, que celebra la "hermosa generación" concebida "para desterrar los males / que por falta della son”, suscitando la admiración por los vástagos reales: “iQué Prinçipe i iqué prinçesa! / ¡qué infantes! ¿qué resplandor / pudo dar cosa mayor / en la tierra a vuestra Alteza / Chisto nuestro redemptor?" 55 .

La figura del príncipe Juan no pasó desapercibida a algunos poetas de la guerra de Granada, como Paolo Pompilio y Ugolino Verino, sin embargo, es en estas fechas cuando el heredero recibe obras expresamente dedicadas como los tratados de Tideo Acciarini y nuestro conocido Pietro del Monte. Acciarini (c. 1430-c. 1490) era preceptor y miembro del Studium de Nápoles cuando compuso el De anima medicamentis (o De animorum medicamentis) con idea de presentarse en la corte del príncipe para exaltar sus futuras hazañas ${ }^{56}$. La obra pudo gestarse en el ambiente pedagógico de la corte napolitana, de la que habían salido los escritos de Diomede Carafa y Francesco Vitale di Noya, que pudieron reactivarse a raíz de las negociaciones entabladas con Ferrante de Nápoles sobre el matrimonio de los infantes ${ }^{57}$. Acciarini incluye en su tratado educativo un encomio de Isabel y el divus Ferdinandus, modelo de prudencia en las previsiones, sabiduría en las deliberaciones, recta administración de la justicia y la santidad y piedad en el cumplimiento de sus deberes religiosos. Con ello enlazaba con la línea legitimista de la propaganda napolitana, especialmente sensible a las tensiones que sufría la dinastía aragonesa con la nobleza del reino y el papado.

A la propaganda del heredero también pertenece el tratado De la naturaleza del hombre de Pietro del Monte, que conocemos gracias a la versión latina realizada por su

\footnotetext{
54 Kolsky, The Ghost of Boccaccio..., p. 100.

55 Véanse más adelante las referencias a este poema.

56 La obra ha sobrevivido en dos manuscritos que el propio Acciarini conservaba; BAV, Vat. Barb. 213; y Vat. Barb. 282. La mayor parte de la obra, tomando exclusivamente el primero de las manuscritos, ha sido editada por Francesco Lo PARCo, Tideo Acciarini humanista marchigiano del secolo XV con sei carmina e un libellus inediti della Biblioteca Classense di Ravenna e della Biblioteca Vaticana, Nápoles, Giannini \& Figli, 1919. Sin embargo existen variantes en ambas fuentes que merecen ser estudiadas; Sergio Sconocchia, "Profilo intellettuale di Tideo Acciarini, maestro di umanità in Dalmazia", en Marche e Dalmazia tra Umanesimo e Barocco, Atti del convegno internazionale di Studi (Ancona-Osimo, 13-15 maggio 1988), Reggio Emilia, Edizioni Diabasis, 1993, pp. 205-218 (a quien agradezco el envío de su artículo).

57 Álvaro Fernández de Córdova, "Diplomáticos y letrados en Roma al servicio de los Reyes Católicos: Francesco Vitale di Noya, Juan Ruiz de Medina y Francisco de Rojas", Dicenda: Cuadernos de filología hispánica, 32 (2014), pp. 113-154.
} 
discípulo Gonzalo de Ayora, publicada en Milán en 1492 con el título De dignoscendis hominibus $^{58}$. Pietro del Monte era un conspicuo representante del humanismo militar al servicio de los Sforza, que tras participar en la campaña de Granada había iniciado la composición de este voluminoso tratado de formación física que Ayora culminará en 1492, incorporándose poco después a la corte de los reyes. La obra proyecta en el joven heredero el prestigio adquirido por sus padres en la campaña granadina, exaltándole como príncipe sabio formado en las técnicas de lucha y digno vástago de una reina que supera al mismísimo Aníbal. La obra de Monte-Ayora es el fruto tardío de una propaganda bélica que ahora se enriquecía con el latín y los hallazgos de la fisionómica humanista. Su éxito editorial y la incorporación a la corte de uno de sus autores, son indicios del interés despertado por la obra en aquel ambiente de turbación internacional.

\section{La parábola fernandina en las "guerras de Italia"}

\subsection{Encrucijada de mesianismos}

Como señalamos al comienzo, la calata de Carlos VIII en Italia no desencadenó un enfrentamiento exclusivamente militar. Diversos autores han devanado la madeja de ideas y corrientes mesiánicas que alentaron las pugnas y trasvases propagandísticos durante el conflicto, identificando a los agentes, sus métodos y vías de transmisión ${ }^{59}$.

En este sentido, las fuentes venecianas señalan que los motivos antiturcos alegados por Carlos VIII para justificar la invasión del reino de Nápoles surgían de un deseo de emulación de la reconquista hispana, pues la sugestión crecía "havendo lo exempio di

\footnotetext{
58 A juzgar por el número de ejemplares conservados, la obra debió contar con apoyo financiero, quizá de la Corona, interesada en esta obra precedida por un prefacio dirigido a la reina; cfr. Marie-Madeleine FonTAINE, "Le condottiere Pietro del Monte et la physiognomonie des soldats engages dans les guerres d'Italie", en Jean Balsamo (ed.), Passer les monts: Francais en Italie - l'Italie en France, París, H. Champion, 1998, pp. 91-109; ID., "Comment Pietro del Monte, condottiere Italien parlait Espagnol", Bibliotheque d'Humanisme et Renaissance, 54 (1992), pp. 163-73. Algunos datos sobre la actividad de Ayora en la corte de los Reyes Católicos en María Concepción Solana Villamor, Cargos de la casa y corte de los Reyes Católicos, Valladolid, Sever-Cuesta, 1962, pp. 61-62; José Luis Villacañas Berlanga, "Palencia y Ayora: de la caballería a la infantería”, en José Javier Ruzz IBÁÑ̃z (coord.), Las milicias del rey de España: sociedad, política e identidad en la monarquías ibéricas, Madrid-México, Fondo de Cultura Económica, 2009, pp. 41-71.

59 Anne Denis, Charles VIII et les italiens: histoire et mythe, Ginebra, Droz, 1979; Alain Milhou, Colón y su mentalidad mesiánica en el ambiente franciscanista español, Valladolid, Casa-Museo de Colón, 1983, pp. 335 y ss; Cesare Vasoli, "Il mito della monarchia francese nelle profezie fra 1490 e 1520", en Dario Cecchetti, Lionell Sozzi, Louis Terreaux (ed.), L'aube de la Renaissance, Gèneve, Slatkine, 1991, pp. 149165; Christian De Merindol, "L'imaginaire du pouvoir à la fin du Moyen Âge: Les prétensions royales", en Joel Blanchard (ed.), Représentation, pouvoir et royauté, à la fin du Moyen Age, París, Picard, 1995, pp. 73-74; Silvio Bianciard, La chimera di Carlo VIII (1492-1495), Novara, Interlinea, 2011. Las corrientes mesiánicas también recuperaron las manifestaciones milagrosas como ha mostrado Noemi Rubello, "Una bella et caritativa cosa. Épisodes de thaumaturgie royale pendant la période des Guerres d'Italie", Le Moyen Âge, 120/1 (2014), pp. 53-77.
} 
quello havea fatto Ferdinando re di Spagna, che il reame di Granata ha acquistato" ${ }^{\circ 0}$. Como han estudiado Alain Milhou, Eulàlia Duran Grau y Joan Requesens, esta hazaña no constituía un mero triunfo militar sino el feliz cumplimiento de la tradición proféticomesiánica de matriz aragonesa, que convertía a Fernando en el rey que acabaría con el Islam, reformaría la Iglesia, reconquistaría Jerusalén y recuperaría el título imperial ${ }^{61}$; elementos todos ellos que encontramos en la propaganda francesa de Carlos VIII, y que Fernando había asumido anteriormente en sus reinos patrimoniales y más adelante en Castilla en la década de 1480, reactivándose durante la guerra de Granada gracias a autores como Alfonso de Jaén o Pedro Marcuello, entre otros ${ }^{62}$.

Sin soslayar los desarrollos proféticos autóctonos, el testimonio veneciano revelaría un fenómeno de contaminación, fruto de la rivalidad mimética y de la intervención de los mismos intelectuales en uno y otro bando. La tan frecuente mercenariedad de la clase intelectual. Es el caso de Ugolino Verino, que abandona su largo poema Carlias dedicado al rey francés, para emprender su De expugnatione Granatae ${ }^{63}$; Carlo Verardi que dos años después de componer su Historia Baetica, usa el mismo recurso dramático para exaltar la conquista de Milán por Luis XII en su De rebus italicis tragoedia ${ }^{64}$; o Jakob Locher (1471-1528), alumno de Sebastian Brant, que en 1495 se inspira en la Historia Baetica para redactar su Historia de rege Franciae dedicada

${ }_{60}$ Marino SAnuto, La spedizione di Carlo VIII in Italia, ed. R. Fulin, Venecia, Tipografia del Commercio di Marco Visentini, 1883, p. 30. Ver también Carlo DE FrEDE, "Più simile a mostro che a uomo", en ID., La crisi del Regno di Napoli nella riflessione politica di Machiavelli e Guicciardini, Nápoles, Liguori, 2006, p. 318.

${ }_{61}$ Alain MiLnou, Colón y su mentalidad mesiánica en el ambiente franciscanista español, Valladolid, Casa-Museo de Colón, 1983. Y el valioso estudio, que incluye una selección de textos proféticos, de Eulàlia DuRAn Grau, y Joan Requesens, Profecia i poder al renaixement: text profétics catalans favorables a Ferran el Catòlic, Valencia, Eliseu Climent, 1997; Martin FrüH, "Profecía y realidad: una oda de Antonio Geraldini al rey Fernando el Católico", en De litteris neolatinis in America Meridionali, Portugallia, Hispania, Italia cultis, Valencia, Frankfurt am Main, 2002, pp. 47-67.

62 A los trabajos citados, cabe añadir los estudios de Pedro Manuel CÁtedra, La historiografía en verso en la época de los Reyes Católicos. Juan Barba y su 'Consolatoria de Castilla', Salamanca, Universidad, 1989, pp. 25 y ss; Rafael Ramos, "El Libro del milenio de fray Juan Unay ¿Una apología de Fernando el Católico?", en Actas del VI Congreso de la Asociación Hispánica de Literatura Medieval, Alcalá de Henares, 1997, pp. 1241-1248; Ana Isabel Carrasco Manchado, Isabel I de Castilla y la sombra de la ilegitimidad: propaganda y representación en el conflicto sucesorio (1474-1482), Madrid, Sílex, 2006, pp. 90, 227, 356, 519 y ss; Rafael G. Peinado Santaella, "El final de la Reconquista: elegía de la derrota, exaltación del triunfo", en Andalucía y Granada en tiempos de los Reyes Católicos, Sevilla, Universidad de Granada, 2006, pp. 55-86; Ángel Gómez Moreno y Teresa Jiménez Calvente, "El reinado de los Reyes Católicos: buenos tiempos para la épica", en José LARA Garrido y Raúl Díaz Rosales (eds.), La épica culta en España, Málaga, Universidad de Málaga, 2014, pp. 1-39.

63 Ugolino Verino, De expugnatione Granatae: (panegyricon ad Ferdinandum regem et Isabellam reginam Hispaniarum de saracenae baetidos gloriosa expugnatione), ed. I. López Calahorro, Granada, Universidad de Granada, 2002, pp. 31-32; Christine Ratкоwiтsch, "Der Seesturm in der Carlia des Ugolino Verino und die spätantike Epik", Mittellateinisches Jahrbuch: internationale Zeitschrift für Mediävistik, 43-1 (2008), pp. 57-80.

64 Antonio StäUble, "Risonanze europee della commedia umanistica del Quattrocento' europee”, en ID., "Parlar per lettera": il pedante nella commedia del Cinquecento e altri saggi sul teatro rinascimentale, Roma, Bulzoni, 1991, pp. 183-195. 
a la lucha de Carlos VIII por Nápoles ${ }^{65}$. Sin embargo, los trasvases propagandísticos no funcionaron de igual manera pues -como ha señalado Guy Le Thiec- los mensajes cruzadistas franceses no superaron el profundo antagonismo ideológico que existía entre las concepciones teocráticas de Alejandro VI y la soberanía monárquica de Carlos VIII ${ }^{66}$; mientras la propaganda hispana conseguía atenuar temporalmente sus motivos de tensión con el Papado gracias a los mensajes de gloria coextensiva que venían difundiéndose desde la elección del segundo papa Borja.

Por encima de este nudo de intereses y creencias profundas, el Papado quiso estudiar las razones jurídicas que esgrimían unos y otros en sus reivindicaciones al reino de Nápoles. En este contexto, se editaron en 1495 dos importantes trabajos que ofrecen elementos de legitimación en favor de la dinastía aragonesa, que acaba de firmar una alianza político-familiar con Alejandro VI gracias a la mediación hispana. Nos referimos al Epitoma de regno Apulice et Siciliae que Felino Sandei redactó por encargo del pontífice ${ }^{67}$; y el Tractatus dialogicus de confoederatione principum et potentatum (c. 1495) que Juan López de Segovia dedicó al cardenal Francesco Todeschini Piccolomini, defendiendo el derecho del papa a aliarse con otros príncipes cristianos, e intervenir militarmente en caso de grave abuso sobre el más débil, como se advertía en el caso napolitano ${ }^{68}$.

Estas obras se editaron en el seno de una Curia dividida, donde el cardenal Bernardino López de Carvajal, antiguo embajador de los monarcas, se atrevía a presentar la sucesión de Fernando de Aragón como sobrino de Alfonso el Magnánimo "caso que d'esta extirpe del preffato don Ferrando [Ferrante de Nápoles] se deviesse quitar", como planteaban los agentes franceses ${ }^{69}$. En este delicado proceso político, Alejandro VI depositó su confianza

65 Dietrich Briesemeister, "Literatura épico-dramática del Siglo de Oro sobre la conquista de Granada: ¿un compromiso poético?", Nueva revista de filología hispánica, 36-2 (1988), p. 938. Sobre la literatura heroica en lengua francesa y latina desplegada a raíz de la campaña de Nápoles Sandra Provini, Les Guerres d'Italie entre chronique et épopée: le renouveau de l'écriture héroïque française et néo-latine en France au début de la Renaissance. Tesis doctoral defendida en 2009 en la Universidad Paris-Diderot.

${ }_{66}$ Guy Le Thiec, "Le roi, le pape et l'otage. La croisade, entre théocratie pontificale et messianisme royal (1494-1504)", Revue d'histoire de l'Église de France, 88 (2002), pp. 41-82.

67 Concetta Bianca, "Le orazioni a stampa", en Maria Chiabò, Silvia Maddalo, y Massimo Miglio (dirs.), Roma di fronte all'Europa al tempo di Alessandro VI. Atti del Convegno (Città del Vaticano-Roma, 1-4 dicèmbre 1999), vol. II, Roma, Roma nel Rinascimento, 2001, pp. 447-448; Vicente Beltrán de Heredia, Cartulario de la Universidad de Salamanca, vol. II, Salamanca, Universidad de Salamanca, 1970, pp. 465467. Los antecedentes de esta polémica en Enrico PISPISA, Regnum Siciliae. La polemica sulla intitolazione, Palermo, Centro di Studi filologici e linguistici siciliani, 1988.

68 Cfr. Xavier Tubau, "Las alianzas a la luz del Derecho Canónico: el Tractatus Dialogicus de confoederatione principum et potentatum (c. 1495) de Juan López de Segovia", Anuario de Estudios Medievales, 40-2 (2010), pp. 537-563. Véanse también las notas de René de Maulde la Clavière, La diplomatie au temps de Machiavel, vol. III, París, Ernest Leroux, 1893, pp. 260-264. Una edición facsímil de la obra citada en Juan López de Segovia, De la confederación de príncipes, y De la guerra y de los guerreros, ed. de F. Antón Moreno y J. Fernández Prida, Madrid, Tipografía de Archivos, 1931; Eulàlia Duran (dir.), Repertori de manuscrits catalans..., p. 244; y el análisis de Vico AllegretTi, Diritto di guerra nel XV Secolo. Il Tractatus De Bello et bellatoribus di Juan Lopez (+1496), Roma, Ufficio storico SME, 2003.

${ }_{69}$ Véase el cap. 91 de la Historia del pontificado de Alejandro VI que comentaremos más adelante. 
en la alianza militar con Isabel y Fernando, a quien había confiado a su hijo Joan de Borja, el duque de Gandía, considerado por el Pistoia "commensale" del rey de España que "venne in tanto amor con la corona / che gli fe dono d'un stato ducale" que conforme se hacía más inminete el descenso de Carlos VIII reclamara insistentemente el envío de la flota prometida, cuya llegada fue celebrada con entusiasmo por los curiales y prelados españoles ${ }^{71}$, y era anunciada solemnemente al Senado veneciano ${ }^{72}$. Y aunque el papa reprochó a los reyes su retraso, barajó la posibilidad de refugiarse en su corte "de la misma suerte, que otros muchos de sus predecesores estuvieron en Francia, cuando sus reyes amparaban las cosas de la Iglesia"73; evasión que también sopesó Alfonso de Nápoles y el duque de Milán, Ludovico Sforza, tras la entrada de las tropas francesas en Italia ${ }^{74}$.

Contemporáneamente se desarrolló en Nápoles una defensa dinástica que exaltaba la continuidad de los Trastámara hispanos y napolitanos, unidos frente al enemigo francés ${ }^{75}$. Se aprovecharon para ello los materiales semánticos de la guerra de Granada en favor del rey Católico identificado con "quell'Aragonio Sol, che d'occidente / saetta con soi rai la gente Maura", como hace Benet Garret, el Cariteo (Soneto CXCV); sin olvidar los emotivos versos de su Endimione que en 1494 lamentaba la tragedia que se abatía sobre Nápoles tras el fallecimiento de Ferrante mientras la "felice Hispagna" gozaba del victorioso Fernando, "l'altro Re de sua vittoria / Contra gente Africana, oscura \& bruna, / Quanto d'una tal luce, hoggi si gloria" (Soneto CXLVI) ${ }^{76}$. Eran los ecos

\footnotetext{
70 Se trata del soneto 154 de Antonio Cammèlli; Renier, I sonetti di Pistoia..., p. 154.

71 Véase el despacho del embajador Pandolfo Collenuccio al duque Hércules I de Este, 30 noviembre 1494, donde anuncia la partida de 50 naves con 10.000 hombres para auxiliar al papa: "Per questa nova tra tutti quelli cubicularij e prelati spagnoli se facea tanta allegrezza che non teneano loco"; Paolo NeGRI, "Le missioni di Pandolfo Collenuccio a Papa Alessandro VI (1494-1498)", Archivio della Società Romana di Storia Patria, 33 (1910), p. 427. El retraso de este contingente militar comprometería gravemente las expectativas depositadas en los monarcas y explica el circunspecto anuncio de su avistamiento en Nápoles en julio de 1495; Riccardo Filangieri (ed.), Una cronaca napoletana figurata del Quattrocento, Nápoles, L'Arte tipografica, 1956, pp. 145-146.

72 Concretamente el embajador anunció la llegada a Sicilia de 30 carabelas y 20 naves con 500 hombres de armas "in soccorso del Re de Napoli contra Francesi”"; Malpiero, Annali veneti..., pp. 327 y 342.

73 Jerónimo de Zurita, Historia del rey don Hernando el Cathólico. De las empresas y ligas de Italia, ed. A. Canellas López, Zaragoza, 1996, libro II, cap. XIV. Fernández de Córdova, Alejandro VI y los Reyes Católicos..., pp. 304-331. Sobre la ambigua política de Alejandro VI ante los hechos consumados de la invasión francesa cfr. Christine Shaw, "Alexander VI and the French Invasion of 1494", Iacobus: Revista de Estudios Jacobeos y Medievales, 25-26 (2009), pp. 197-221.

74 Concepción Villanueva Morte, y Álvaro Fernández de Córdova Miralles, Juan Claver, embajador de los Reyes Católicos en la Italia del Renacimiento (en preparación).

75 La relación de Fernando con sus parientes napolitanos en la última década del siglo XV cuenta ahora con la importante investigación de Ivan PARISI, La corrispondenza italiana di Joan Ram Escrivà, ambasciatore di Ferdinando il Cattolico (3 maggio 1484 - 11 agosto 1499), Battipaglia, Laveglia \& Carlone, 2014.

76 Erasmo Pèrcopo, Le rime di Benedetto Gareth detto il Chariteo: secondo le due stampe originali Cariteo, Nápoles, Tipografia dell'Accademia delle Scienze, 1892, pp. 174-175; y las correcciones de Rino Consolo, "Il libro di Endimione: modelli classici, inventio ed elocutio nel canzoniere del Cariteo", Filologia e Critica, 3 (1978), p. 92; Joaquín ARCE, Literaturas Italiana y Española frente a frente, Madrid, Espasa-Calpe, 1982, p. 94; William J. Kennedy, "Citing Petrarch in Naples: The Politics of Commentary in
} 
poéticos de una alianza que justificaba el traslado a España del nuevo rey de Nápoles, Alfonso II, para combatir desde allí a los franceses ${ }^{77}$, pues "ancor si dice che " 1 Re di Spagna / fa gente contra a chi " 1 Re Alfonso offende" ". Al año siguiente, tras la firma de la Liga Santa, el beato Tomassuccio anunciaría la destrucción de la "gallica lancia" por la "multa gente" de la nueva Liga Santa ${ }^{79}$. Se llegaba así a la cristalización de dos grandes bloques y la decantación de las pequeñas potencias como Pisa, que permaneció "col re di Napoli, e colla Chiesa", esperando "il soccorso del Re di Spagna"80.

La coalición de las potencias italianas, los monarcas hispanos y el rey de Romanos contaría con su propia propaganda en forma de espectáculos urbanos, como el que se celebró en la plaza veneciana de San Marcos el 12 de abril de 1495. En la procesión organizada por la Señoría desfilaron Isabel y Fernando -"vestiti alla castigliana da driedo" y portando una espada- sobre un carro con una inscripción latina que anunciaba la prosperidad de su reinado: "Dies super dies regis adjices" y unos versos que recordaban sus hazañas granadinas: "De infedeli hanno fatto gran ruina" ${ }^{81}$. No hay que olvidar que los éxitos granadinos suponían una importante nota legitimadora aportada por los monarcas hispanos a aquella coalición que presentaba a Carlos VIII como enemigo de la Cristiandad. De ahí que en su discurso pronunciado en Roma por la firma de los acuerdos, Leonello Chieregato destaque como algo propio de los reyes hispanos su animosidad hacia los enemigos de los cristianos, que los convierte en insignes representantes de la república cristiana y de una Liga a la que aportan su "immensam potentiam" y sus "laudes inmortales" celebradas con "amplissimo consensu" 82 .

La propaganda antifrancesa no era novedosa en la corte de Isabel y Fernando. Comenzó a despuntar durante la campaña del Rosellón, dejando huellas en las Coplas de la Pasión con la Resurrección del comendador Román, donde se anuncia el aplastamiento de la "flor de lis" por el "león" Fernando y el "águila" Isabel, acudiendo a las profe-

Cariteo's Endimione", Renaissance Quarterly, 55-4 (2002), pp. 1196-1221; Gabriella SCARLATTA Eschrich, "Cariteo's Aragonia: The Language of Power at the Aragonese Court", Forum Italicum: A Journal of Italian Studies 37 (2003), pp. 329-344.

77 Véanse los despachos de Donato Preti, embajador de Francesco Gonzaga, desde Milán, 7 y 12 febrero 1495; Franca Leverotti (dir.), Carteggio degli oratori mantovani alla corte sforzesca (1450-1500), vol, XV: 1495-1498, ed. de A, Grati y A. Pacini, Roma, Ministero per i Beni Ambientali, Pubblicazioni degli Archivi di Stato, 2002, pp. 97 y 102.

78 Versos del citado Antonio Cammèlli (soneto 314), en Renier, I sonetti di Pistoia..., p. 314.

79 "La gallica lancia / Non varrà una paglia: / Lassa in travaglia / Chiascuno suo aderente. // Trarà multa gente / Ad quisto adversaglio / Uno sono de sonaglio / Li cacciarà del ballo"; versos recogidos en la crónica de Francesco Mugnoni, Annali di ser Francesco Mugnoni da Trevi, dall'anno 1416 al 1503, ed. de P. Pirri, Perusa, Unione tipografica cooperativa, 1921, pp. 102-103. Sobre la propaganda de guerra francesa cfr. Vicente L. Salavert Fabiani, "La política exterior de Fernando el Católico a la luz de la literatura polémica hispano-francesa de su tiempo", en Esteban SARASa (coord.), Fernando II de Aragón, el Rey Católico, Zaragoza, Institución Fernando el Católico, 1996, pp. 539-553.

80 Parenti, Storia fiorentina..., vol. I, p. 132.

81 SAnuto, La spedizione di Carlo VIII..., p. 301.

82 Leonello Chieregato, Sermo in publicatione confoederationis inter Alexandrum VI et Romanorum et Hispaniae reges Venetorumque ac Mediolanensium duces, ed. Johann Besicken, Roma, 1495; en BAV, Inc. IV 399; también Inc. Ross. 1230. 
cías atribuidas a Crisóstomo y a Rocatallada ${ }^{83}$. La temática se reactivó a medidados de 1495 ante la calata de Carlos VIII, mediante el género dramático que había alcanzado importantes desarrollos en la corte napolitana y pontificia ${ }^{84}$. Se trata de la égloga de Francisco de Madrid que pudo representarse en el entorno papal aportando la novedosa combinación de la forma teatral con una alegoría política descubierta ${ }^{85}$. En ella se desarrolla un mensaje pacifista frente a la agresión francesa y una ambigua alabanza de Fernando como defensor del Papado tocado de ciertas notas de soberbia y belicosidad. Sin duda un material justificativo para convencer a los embajadores presentes en la Curia -como opina Gillet-, o despejar los recelos castellanos -como opina Surtz- a destinar sus recursos contra su tradicional aliado, como refleja el comentario del duque de Nájera cuando fue informado por el rey Fernando: "para tan gran páxaro [Carlos VIII de Francia], poca liga es" ${ }^{\text {. }}$.

Con todo hubo que esperar a las primeras acciones bélicas de Gonzalo Fernández de Córdoba en suelo napolitano ${ }^{87}$, y a la apertura de un segundo frente militar en la frontera del Rosellón a fines de 1495 para que comience desplegarse la propaganda bélica desde la corte de Isabel y Fernando destacando que sus tropas mostraban "gran respetto a le giesie e alle persone che s'havea salvà in esse" ${ }^{\prime 8}$. Si en el primer caso se enfatizaba la potencia militar de la ayuda española, en el segundo se mostraba su fidelidad a los compromisos asumidos con las potencias de la Liga, especialmente desde que empezaran a escucharse los reproches del papa y el duque de Milán por la tardía comparecencia de las tropas españolas ${ }^{89}$. Imagen negativa que trató de paliarse más tarde mostrando los

\footnotetext{
83 Identificado por Giuseppe Mazzochi como el toledano Diego Román, criado de los reyes y contino de Isabel en 1493; cfr. Comendador Román, Coplas de la Pasión con la Resurrección, ed. de Giuseppe Mazzocchi, Florencia, La Nuova Italia, 1990, pp. 92-93; también Ana Isabel CARRASCO MANCHADO, "Propaganda política en los panegíricos poéticos de los Reyes Católicos: una aproximación", Anuario de Estudios Medievales, 25 (1995), p. 541.

84 Cfr. Joseph E. Gillet, "Égloga hecha por Francisco de Madrid (1495?)", Hispanic Review, 11 (1943), pp. 275-281; Antonio Blecua, "La Egloga de Francisco de Madrid en un nuevo manuscrito del siglo XVI", en Serta Philologica F. Lázaro Carreter, vol. II, Madrid, Cátedra, 1983, pp. 39-66; Ronald E. SuRTZ, Teatro castellano de la Edad Media, Madrid, Taurus, 1992, pp. 48-51; Federica Accorsi, "La égloga de Francisco de Madrid: un ensayo bucólico de finales del s. XV", en Natalia Fernández Rodríguez y María Fernández FERREIRo (ed.), Literatura medieval y renacentista en España: líneas y pautas, Oviedo, SEMYR, 2012, pp. 333-340.

85 Federica Accorsi, La égloga de Francisco de Madrid..., p. 337.

86 Floreto de anécdotas y noticias diversas..., p. 336.

87 Véase el protagonismo militar que va asumiendo "Consalvo Ferrante Capitano" a lo largo de 1496 en la correspondencia del comandante del ejército aliado, Francesco II Gonzaga, marqués de Mantua; Giuseppe Coniglio, "Francesco Gonzaga e la guerra contro i francesi nel regno di Napoli", Samnium, 34 (1961), pp. 15 y $17-18$.

88 Despacho diplomático de los embajadores venecianos Francesco Capello y Zaccari Contarini resumidos por Malpiero, Annali veneti..., pp. 416-417. Sobre la organización de ambas campañas resulta fundamental el trabajo de Miguel Ángel Ladero Quesada, Ejércitos y armadas de los Reyes Católicos: Nápoles y el Rosellón (1494-1504), Madrid, Real Academia de la Historia, 2010.

89 En 1495 Ludovico el Moro se quejaba de que Isabel y Fernando aún no habían enviado un solo hombre a defender el ducado de Milán; Villanueva Morte, y Fernández de Córdova Miralles, Juan Claver, embajador de los Reyes Católicos (en preparación).
} 
esfuerzos de los monarcas por pacificar, con las restantes potencias aliadas, la revuelta de Pisa sostenida por Venecia ${ }^{90}$. Al año siguiente, la incorporación de Enrique VII a la liga antifrancesa dio pie a la celebración en Roma de una Misa solemne y procesión -"come si fa "l zorno del Corpus Domini"-, con la pronunciación de una oratio a cargo de Adriano Castellesi (31.VII.1496) ${ }^{91}$, cuatro días antes de que el ejército francés capitulara en Atella (27.VII.1496), donde Fernández de Córdoba comenzó a recibir el título de "Gran Capitán"92.

La inicial propaganda antifrancesa se cargó de argumentos histórico-religiosos en el Tratado endereçado a la reina nuestra señora sobre la guerra de Francia finalizado en noviembre de 1497 por el jurado Juan Núñez de Madrid. Su objeto era justificar la guerra con el país vecino equiparando su soberbia con la infidelidad de los turcos ${ }^{93}$. Se reutilizaban así antiguos materiales propagandísticos para justificar el conflicto mediante pasarelas ideológicas. La imagen de Fernando se benefició de ello. Sobre el modelo de Valerio Máximo fundado en la disciplina, Juan Núñez recupera la silueta fernandina de la guerra de Granada y la faceta providencialista expresada en su rectitud moral, "pues sobra su Alteza en fe y virtudes a todos estos reyes y emperadores". Sin embargo, la publicación del Tratado debió esperar siete años, pues el jurado finalizó su obra durante la crisis sucesoria que condujo a la firma de las treguas con Francia en febrero de 1498. La publicación de este alegato bélico no podía ser más inoportuna entonces y tuvo que esperar a 1504 para publicarse entonces triunfalista de la segunda campaña de Nápoles. Una incipiente historiografía sobre las "guerras de Italia" también comenzó a gestarse al calor de las hazañas militares. Se trata de obras perdidas o inconclusas cuyo alcance no podemos valorar. A fines del siglo XIX, Isidoro Carini identificó entre las crónicas conservadas en la Biblioteca Nacional una Storia latina del passaggio di Carlo VIII in Italia e del tempo del Gran Capitano de la que no tenemos mayor noticia ${ }^{94}$; y Vincenzo Calmetta (1460-1508), poeta al servicio de los Borja, emprendió una Istoria desde la caída de Constantinopla (1453) hasta la invasión de Luis XII en 1502, que incluía un libro octavo sobre la defensa de Nápoles gracias a la acción coordinada del rey Ferrantino, el Gran Capitán y el embajador Garcilaso de la Vega ${ }^{95}$.

\footnotetext{
90 Véanse los versos del Pistoia en Renier, I sonetti di Pistoia..., pp. 326, 331 y ss.

91 Ibidem, p. 439; Luigi De Pascalis, "L'Oratio pronunciata da Adriano Castellesi in Santa Maria del Popolo per la pubblicazione della Lega Santa (31 luglio 1496)", en Roma, donne libri tra medioevo e rinascimento. In ricordo di Pino Lombardi, Roma, Roma nel Rinascimento, 2004, pp. 287-301.

92 José Enrique Ruiz-Domènec, El Gran Capitán. Retrato de una época, Barcelona, Península, 2002, pp. 282-287.

93 Gómez Redondo, Historia de la prosa de los Reyes Católicos..., vol. I, pp. 341-346.

94 Isidoro CARINI, Gli archivi e le biblioteche di Spagna in rapporta alla storia d'ltalia in genérale e di Sicilia in particolare, Palermo, Tipografia dello Statuto, 1885, p. 217.

95 Nos referimos a la Istoria della varietà della foruna de' tempi suoi de la que se ha conservado una guión con breves anotaciones de los principales personajes; cfr. Vincenzo CALmeta, Prose e lettere edite e inedite: con due appendici di altri inediti, ed. de Cecil Grayson, Bologna, Commissione per i testi di lingua, 1959, pp. 118-120.
} 
Lo que para algunos era motivo de exaltación patriótica para otros constituía la actualización de las antiguas profecías. En esta línea se sitúa Jeroni Torrella (1450-1508), filósofo neoplatónico, astrólogo y médico de Alejandro VI que reinterpretó los vaticinios fernandinos en clave astrológica en el De imaginibus astrologicis (Valencia, 1496) que dedicó al rey Católico a través de su embajador en Nápoles Joan Ram Escrivà ${ }^{96}$. En su prólogo De rege valentino le atribuye la profecía Surge, Vespertilio, surge, surge, identificándole con el murciélago escatológico que acabaría con el Islam y el Judaísmo en España, para después conquistar África, el Oriente y la Santa Casa. Torella añade a estos elementos, los argumentos astrológicos de autoridades judías y musulmanas que anunciaban años de calamidades hasta el triunfo del monarca universal y la implantación de una sola fe que una a los hombres. Tales inquietudes debieron encontrar un fecundo caldo de cultivo en el Reame en aquel mismo año en que las tropas hispanonapolitanas se habían impuesto al ejército francés y el propio rey Católico presentaba su candidatura al reino tras el repentino fallecimiento de Fernando II de Nápoles (7.IX.1496), con el que había acordado el traspaso del reino con la aquiescencia de Venecia y el romano pontífice ${ }^{97}$. Con razón, podía decir el poeta Antonio Cammèlli que en aquellos meses de incertidumbre "il cielo è in Gallia de' sogni dipinto / e quel di Spagna di speranza tinto"98.

\subsection{Expansión africana y sueños de unidad mediterránea}

Con el final de la guerra de Granada, el ideal cruzadista continuó desarrollándose a la sombra del proyecto norteafricano impulsado por los acuerdos de Tordesillas (7.VI.494) y la concesión de la bula Ineffabilis et summi (13.II.1495) que investía a los reyes con el dominio de las tierras conquistadas en África. En un momento en que la empresa indiana revelaba su rostro más amargo tras el segundo viaje de Colón, el Mediterráneo recuperó el prestigio de tiempos de Enrique IV de Castilla como tierra de expansión

\footnotetext{
96 Sobre este personaje cfr. Jon Arrizabalaga, Fernando Salmón, y Luis García Ballester, "La medicina valenciana y sus relaciones con Italia entre 1470 y 1520: estudiantes valencianos en los estudios generales de Siena, Pisa, Ferrara y Padua", en Manuel Ardit (ed.), Lluís de Santàngel i el seu temps, València, Ajuntament de València, 1992, pp. 387-400; Anna Maria Oliva, y Olivetta SchenA, "I Torrella, una famiglia di medici tra Valenza, Sardegna e Roma”, en Maria Chiabò, Anna Maria Oliva, Olivetta Schena (coord.), Alessandro VI dal mediterraneo all'atlantico, Roma, Roma nel Rinascimento, 2004, pp. 115-146. Su dimensión profética y propagandística en Milnou, Colón y su mentalidad mesiánica..., pp. 381-382 y 393; y Duran Grau, y REQuesens, Profecia i poder al renaixement..., pp. 369-384.

97 El patricio veneciano Malpiero se mostraba consciente de ello cuando al describir la enfermedad del rey napolitano comenta que "in caso che'l muora senza fioli, per il patto delle noze [de Fernando II con su tía paterna Juana de Nápoles, hija de Fernando I y de su segunda esposa, Juana de Aragón, hermana del rey Católico], il Regno pervien in la corona de Spagna"; Malpiero, Annali veneti..., pp. 379 y 471. Sobre este complejo episodio cfr. Fernández de CóRdova, Alejandro VI y los Reyes Católicos..., pp. 351-354; y la tesis de Ivan Parisi, Ram Escrivà, ambasciatore spagnolo presso la corte di Napoli: uno sconosciuto protagonista delle guerre d'italia alla fine del quattrocento, Università degli Studî Suor Orsola Benincasa, Nápoles, 2009. 98 Soneto 338 en Renier, I sonetti di Pistoia..., p. 338.
} 
hacia Oriente ${ }^{99}$. El ambiente romano había sido roturado por el prelado humanista Rodrigo Sánchez de Arévalo con sus discursos ante Calixto III (1456) o Pío II (1458) y en su oratio por la recuperación de Gibraltar en 1462, donde afirmaba que Enrique IV pensaba dirigirse "contra toda África que, por la multitud de sus provincias, pueblos y reinos abarca la tercera parte del orbe habitable" 100 . Treinta años después, el proyecto norteafricano adquiría una nueva actualidad gracias al dominio del litoral andaluz y la inestabilidad política del Magreb: "todo el país -escribía Fernando de Zafra en abril de 1494 refiriéndose a las potencias magrebíes- está en un estado de espíritu tal que parece que Dios quiera darlo a sus majestades"101. La nueva sensibilidad se transmitió a la literatura laudatoria de aquellos años, como el poema latino, autotraducido y glosado en romance, que un clérigo dirigió a los reyes por encargo de su mayordomo mayor, Gonzalo Chacón, entre 1494 y $1495^{102}$. En él se comenta el inminente sometimiento de los "moros dallende y de Fez", anunciando la ocupación de Numidia "con vuestra fuerça valiente", como un paso para la expulsión de los musulmanes y la recuperación del Santo Sepulcro que -como era costumbre- debía anunciarse en la Ciudad Eterna enviando "un epithoma / de vuestros triunfos a Roma / y esclavos como dacá"103.

Entre los nuevos corifeos africanistas se halla Niccolò Scillacio que, tras sus primeras aportaciones a los descubrimientos atlánticos, vuelve su atención al Mediterráneo en su obra histórica De rebus Tunitis et eorum discordiis intestinis dedicada a Fernando el Católico ${ }^{104}$.

99 La dialéctica entre la empresa indiana y la africana se plantea en el memorial portugués entregado a la reina hacia 1494, donde se le aconseja abandonar la primera y continuar la segunda; cfr. Szaszdi LeonBorja y Katalin Klimes-SzmiK, El memorial portugués de 1494: una alternativa al Tratado de Tordesillas, Madrid, Testimonio Compañía Editorial, 1994. Los ecos literarios del anhelo africano y jerosolimitano en Jacobo Sanz Hermida, "Cancioneros y profecía: algunas notas sobre el mesianismo durante el reinado de los Reyes Católicos", Via Spiritus, 6 (1999), pp. 7-25. Sobre las operaciones militares remito a la síntesis de Mercedes García Arenal y Miguel Ángel Bunes Ibarra, Los españoles y el Norte de África. Siglos XVXVIII, Madrid, 1992; y el trabajo de Miguel Ángel Ladero Quesada, "Melilla en 1494: el primer proyecto de conquista", en Hacer historia desde Simancas. Homenaje a José Luis Rodríguez de Diego, Valladolid, Junta de Castilla y León, 2011, pp. 447-466.

${ }^{100}$ Rodrigo Sánchez de Arévalo, Discursos al servicio de la Corona de Castilla, ed. A. López Fonseca y J. M. Ruiz Villa, Madrid, Escolar y Mayo, 2013, pp. 188-191.

${ }_{101}$ Tomo la cita del clásico artículo de Fernand Braudel, "Los españoles y áfrica del Norte desde 1492 a 1577”, en ID., En torno al Mediterráneo, Barcelona, Paidós, 1997, p. 55. Sobre la actividad de Zafra cfr. Miguel Ángel Ladero Quesada, Hernando de Zafra: secretario de los Reyes Católicos, Madrid, Dykinson, 2005.

102 El poema fue encargado por el influyente mayordomo y consejero de la reina, que debió hacerlo llegar con motivo de su estancia en Madrid entre 17 septiembre del 1494 y el 22 de mayo de 1495, como se deduce de su encabezamiento. Al entorno de los Chacón habían pertenecido intelectuales como Diego Rodríguez de Almela, aunque la referencia del epitoma romano conecta con el entorno del cardenal de Mendoza, especialmente Diego de Muros II que se hallaban en plena actividad propagandística. El poema, conservado en el Archivo del Monasterio de Guadalupe, fue editado por Alejandro AmAro, "Una poesía inédita de Fr. Iñigo de Mendoza y de Jorge Manrique", Archivo Iberoamericano, 4 (1915), pp. 127-130.

${ }_{103}$ El texto latino desarrolla un poco más el dominio sobre los Mauros Numidasque superbos, anunciando su extensión a los antiguos territorios cartagineses, la Cirenaica y el Nilo egipcio ("longi flumina Nili").

104 Giacomo Ferraù, "Traiettoria mediterranea di Nicolò Scillacio", en Amedeo De VincentiIs, Massimo Miglio, y Anna Modigliani (coord.), Roma e il papato nel Medioevo. studi in onore di Massimo Miglio, vol. II, Roma, Edizioni di storia e letteratura, 2012, pp. 194-195. 
Aunque el autor trata de la empresa africana establece un sutil vínculo con los éxitos de la campaña de Nápoles, dotando al victorioso soberano de los apelativos rex cordatissime, Christianae societatis culmen, e Italiae salvator. Con ello Scillatio no sólo legitima su intervención militar en Italia sino que anuncia el éxito del plan propuesto en su tratado. Concretamente, el humanista milanés le exhorta a continuar las operaciones iniciadas en Djerba (1496-1498) aprovechando las discordias entre los hafsíes para continuar la cruzada sin derramamiento de sangre. Este hecho, considerado providencial, permitiría al rey lograr lo que ni Federico Barbarroja, ni Alfonso el Magnánimo consiguieron: consolidar una cadena de posesiones insulares en el Mediterráneo en dirección a Tierra Santa. Fernando asumía el patrimonio simbólico de los grandes soberanos mediterráneos, desde los Hohenstaufen a los Trastámara en una línea ascensionista que debía llevarle hasta Jerusalén.

La fascinación africana también aparece en textos literarios incorporados al corpus narrativo elaborado en ambiente romano. Es el caso de la "Breue destruycion de africa" con que Diego Guillén de Ávila finalizó su Panegírico en alabanza de la reina Isabel en julio de $1499^{105}$. Se trata de las últimas estrofas de la "tercera parte [de la obra] de lo venidero" que el autor culmina "profetizando que vuestras altezas ganaran por África hasta Jerusalem". El familiar del cardenal Orsini anuncia la caída de las tres Mauritanias, Numidia, Cartago y Getulia hasta el país de los etíopes, introduciendo una exaltación alegórica de la fauna y los lugares míticos de la geografía norteafricana, desde el Monte Atlante hasta el templo de Amón. Se comenta la ocupación de Libia y Egipto, para pasar después a las provincias sirias "que tiene el soldán", con la Idumea, Samaria y Palestina, incluida Jerusalén. La utopía del poeta castellano no se ciñe, sin embargo, al dominio militar, pues anuncia un nuevo dominio de paz y justicia en la cuenca mediterránea, donde "la firmeza de su pensamiento / será perdonar los mansos sujetos / domar los infieles soberuios y necios"; una especie de edad idílica proyectada ahora en el Mediterráneo, ensamblando el sueño de una monarquía universal y el ideal romano de un mediterráneo unido bajo el dominio de los Reyes Católicos ${ }^{106}$. Posiblemente estamos ante una de las primeras elaboraciones de la utopía mediterránea que una década después retomarán Tommaso Fedra Inghirami y el Cariteo para celebrar las conquistas de Bugía y Trípoli por el rey Católico.

En este contexto también debió redactarse el Tractado de Roma que Martín Martínez de Ampiés incluyó en su traducción del Viaje de la Tierra Santa de Bernardo de Breidenbach (Zaragoza, ed. de Paulus Hurus, 1498) dirigida a Juan de Aragón, virrey de Cataluña y conde de Ribagorza. El hidalgo aragonés intercala en la traducción sus propios comentarios, exaltando a los Reyes Católicos por su lucha contra los musulmanes en "empresas tan fazañosas" y estableciendo una curiosa relación de España y

\footnotetext{
${ }^{105}$ Diego GuIlLÉn De Ávila, Panegírico en alabanza de la reina Isabel, ed. facsímil de la Real Academia Española, Madrid, 1951, ff. cii y ss. Sobre la identidad del autor remitimos al citado trabajo de Nicasio Salvador Miguel.

106 Otros ejemplos literarios coetáneos que se ajustan a este modelo político en Gómez Redondo, Historia de la prosa de los Reyes Católicos..., vol. II, pp. 1802-1820.
} 
los países de Oriente, reproducidos en excelentes grabados y dibujos ${ }^{107}$. Para Ampiés, el llamamiento de Bernardo de Breidenbach a tomar las armas, debe traducirse en dejar "a nuestro rey don Fernando seguir su enpresa que tiene con gana contra dicha perfida gente, que según las fuerzas de su poderío y la voluntad a la religión cristiana en pocos días puede hazer tanto en los affricanos que más pareciese potencia divina que saber y fuerça de los mortales" ${ }^{108}$. Los monarcas se sitúan así entre los dos grandes centros de la Cristiandad: Jerusalén - la ciudad del sepulcro de Cristo-y la Urbe papal, escogida "por tener su vicario [...] para despensero de sus tesoros". A ellos les corresponde unir ambos extremos separados por el espacio africano que debe recuperarse para la Cristiandad.

Mayor tensión escatológica respira el Conpendio universal de las istorias romanas -redactado antes de 1497 por un servidor áulico- que inserta el reinado de los Reyes Católicos y el papado Borja en el escenario de un Mediterráneo amenazado por los otomanos en un clima con fuertes tintes apocalípticos que se remonta al período de las cruzadas $^{109}$. El autor reconstruye la relación de papas y emperadores para llevar a cabo esta guerra secular, extractando al final de su obra algunas cartas que se intercambiaron para exhortar a unos y otros a convocar una expedición para frenar al Islam.

En el mismo año de 1497 el humanista Pomponio Leto -aclamado profesor del Studium Urbis- culminaba en Roma su Romanae historiae compendium dedicado al cardenal valenciano Francisco de Borja y editado póstumamente en Venecia en $1499^{110}$. En su reconstrucción de la antigüedad tardía, el director de la Academia Romana postula una especie de primado mundial del Papado en los primeros siglos del cristianismo y, en un repentino salto al presente, describe a "Ferdinandus Rex Hispaniarum" como el único monarca cristiano que ha emprendido una guerra justa a diferencia de los otros príncipes que en vez de unirse "sub uno signo crucis" se enfrentan en guerras civiles ${ }^{111}$. Pomponio pondera la "ingenita virtus" del aragonés que, auxiliado por la divinidad, ha logrado vencer y dominar a sus enemigos, poniéndoles en fuga o sometiéndoles bajo su yugo, obteniendo así la palma de la divina inmortalidad. Estas proezas referidas a la campaña granadina y norteafricana ofrecen además una sutil legitimación de la inter-

\footnotetext{
107 Véase el facsímil Bernhard von Breydenbach, Viaje de la Tierra Santa, traducido y comentado por Martín Martínez de Ampiés, Madrid, Ministerio de Educación y Ciencia, Dirección General de Archivos y Bibliotecas, Instituto Bibliográfico Hispánico, 1974; Martín MARTínez de Ampiés, Tratado de Roma [1498], ed. de Pedro Tena Tena, Madison, Hispanic Seminary of Medieval Studies, 1992. Y la reciente edición, fruto de la tesis doctoral dirigida por Nicasio Salvador Miguel, de Bernardo DE BReIDEnBACH, Viaje de la Tierra Santa, ed. P. Tena Tena, Zaragoza, Institución Fernando el Católico, 2003.

108 Breydenbach, Viaje de la Tierra Santa..., parte II, ff. cxxxix-cxl.

109 BNE, Ms. 10448, especialmente f. 219rv; cfr. Gómez Redondo, Historia de la prosa de los Reyes Católicos..., vol. I, pp. 223-231. Y los comentarios de MiLhou, Colón y su mentalidad mesiánica..., pp. 13-29; José Guadalajara Medina, El anticristo en la España medieval, Madrid, Laberinto, 2004, p. 152.

110 Sobre esta obra cfr. Francesco NiutTA, "Il Romanae historiae compendium di Pomponio Leto dedicato a Francesco Borgia", en Davide Canfora, Maria Chiabò, Mauro de Nichilo (dirs.), Principato ecclesiastico..., pp. 353-354. Sobre el cardenal y sus contactos con los Reyes Católicos cfr. Fernández de Córdova, Alejandro VI y los Reyes Católicos..., pp. 107-108.

111 Tomo el texto de los párrafos transcritos por Vladimiro Zabughin, Giulio Pomponio Leto. Saggio critico, vol. I, Roma-Grottaferrata, La Vita letteraria, 1909-12, pp. 228-229.
} 
vención en Italia al implorar a Dios que prolongue las victorias del rey pacificando la tensión internacional mediante una obra santa y laudable que merecerá nuevas coronas para él y su esposa.

El universalismo de tintes nacionalistas llegaría a su máxima expresión en la Crónica de Aragón (Zaragoza, 1499) de Gauberto Fabrizio de Vagad, cuyo prólogo se compuso en fechas posteriores a la renovación de las treguas de $1498^{112}$. Con su exaltado aragonesismo, este historiador oficial describe al rey Católico como dominador del escenario mediterráneo en un momento en que la máxima autoridad espiritual y temporal, el emperador y el papa, "le tienen por cabeça de todo el negocio dellos" pues "vemos como la Liga [Santa] está como puesta en manos de sólo el rey de Hespaña"113. Vagad contempla la extensión del poder hispano en el reino de Nápoles y en la misma Roma, pues de sus bastardos hace reyes (Ferrante de Nápoles) y de sus criados hace papas (Calixto III y Alejandro VI). Con todo, el cronista no reduce los objetivos fernandinos a la península italiana sino que los amplía a África, "que ya fuera toda vasalla de españa si el rey de francia no se atrauessara [y] la siempre discorde y tan renzillosa ytalia no zizañara". En sus sueños universalistas también expresa su estupor ante los descubrimientos atlánticos que son incorporados a la narrativa histórica, quizá por primera vez, como hazañas que superan las de los héroes antiguos.

\subsection{En defensa del Papado: de salvator Italiae $a$ liberator Urbis}

La activación de la campaña africana y la intervención militar en Italia, fueron los recientes acontecimientos recordados en la bula de concesión del título de Reyes Católicos, datada el 16 de diciembre de 1496. Se llegaba al final de una maduración político-simbólica en que Fernando había pasado de defensor de la Cristiandad (guerra de Granada) y salvator Italiae (campaña de Nápoles), a una nueva condición de defensor del Papado que le puso en bandeja un título que desbancaría al Cristianísimo rey francés de su primacía en el imaginario político de la Cristiandad ${ }^{114}$. Aunque la concesión del título se gestionara en los preliminares de la primera campaña de Nápoles, su efectiva concesión sólo se produjo ante la promesa de los reyes de auxiliar militarmente al papa ante los focos de rebeldía que desestabilizaban sus Estados: especialmente los Orsini y la guarnición de Ostia que sometía a la ciudad de Roma a un duro bloqueo de alimentos.

\footnotetext{
112 Gauberto Fabricio de VAGAD, Corónica de Aragón, ed. facsímil de Carmen Orcástegui Gros, Zaragoza, Cortes de Aragón, 1996. Los comentarios de Robert B. TATE, Ensayos sobre la historiografía peninsular del siglo XV, Madrid, Gredos, 1970, pp. 263-279. Sobre las fechas de composición y edición cfr. Miguel Ángel Pallarés Jiménez, "La Crónica de Aragón, de Gauberto Fabricio de Vagad, una cuestión de Estado: sobre el encargo de su redacción y de los problemas para ser impresa", en Javier Guijarro Ceballos (coord.), Humanismo y literatura en tiempos de Juan del Encina, Salamanca, Ediciones Universidad de Salamanca, 1999, pp. 409-422.

113 VAgad, Corónica de Aragón..., ff. Biiiv-Biiiir.

114 Nos ocupamos de este tema con nueva documentación en Fernández de Córdova, Alejandro VI y los Reyes Católicos..., pp. 179-182 y 354-355; ID., Reyes Católicos: mutaciones y permanencias..., pp. 146-154.
} 
El papa otorgó el título a las personas de los reyes y no a sus descendientes, a pesar de los intentos que hubo en este sentido. La concesión emitida en pleno consistorio no sólo sustituía el apelativo habitual de "ilustres" por el de "católicos", sino que se reemplazaba el elenco de los reinos por el título de "rey y reyna de España"; una decisión que Isabel y Fernando habían desechado en $1479^{115}$ y que la Santa Sede se adelantaba a reconocer atendiendo probablemente a la unificación política. Como ha señalado José Manuel Nieto Soria, asistimos a una proyección de la España histórica en una España política $^{116}$; fenómeno que desarrollaban contemporáneamente otros intelectuales italianos como Annio de Viterbo en su quimérica reconstrucción de la antigua Etruria como base histórica de los Estados papales. No es casualidad que sus Antiquitates editadas en Roma en 1498 gracias al patrocinio de Garcilaso de la Vega y el cardenal Carvajal, vinieran precedidas por un prefacio exaltando la política religiosa de los Reyes Católicos ${ }^{117}$.

En 1505, el napolitano Oliviero destacaría la dimensión propagandística de aquella concesión otorgada para "che per tucta la Cristianita se divulgasse, et ad dicti Re et Regina se intitulasse; il qual tanto piu dignio et piu excellente extimare se deve, quanto mai si trova ni a Ri di Hispagnia, ni ad altro prencepe cristiano, esser da la S. Ecclesia Romana in publico consistorio concesso" "118. Datos posteriores confirman el interés de Fernando por este tipo de reconocimientos papales que aseguraban sus derechos y

\footnotetext{
115 Pulgar, Crónica de los Reyes Católicos, ed. de J. de M. Carriazo, vol. I, Madrid, Espasa-Calpe, 1943, p. 369. El rechazo del título de reyes de España no impedía que fuera empleado en otros contextos historiográficos o formas de tratamiento cortesano; cfr. José Manuel Nieto SoRIA, "Conceptos de España en tiempos de los Reyes Católicos", Norba. Revista de historia, 19 (2006), pp. 115-116.

116 Así lo explica Diego Espés cuando precisa que la concesión llevaba consigo un cambio de nombre, pues los reyes dejaban de titularse "reyes de Aragon, Leon y Castilla, y despues de la conquista del reyno de Granada, como eran señores de la provincia que los romanos llamaron Citerior con la Betica y parte de Lusitania, se havia mandado por el mismo Papa Alejandro mudar en el titulo de Reyes Ilustres de las Españas, proveyo por un breve apostolico que de aqui adelante se intitulasen Reyes Catholicos de las Españas"; en Historia eclesiástica de la Ciudad de Zaragoza, en Real Academia de la Historia [RAH] (Madrid), 9/5251; Colección Troggio, vol. 33, f. 177rv. Este testimonio es coincidente con el de Jerónimo DE Zurita, Historia del rey don Hernando el Cathólico. De las empresas y ligas de Italia, ed. A. Canellas López, Zaragoza, 1996, libro II, cap. XXLI. Tras el fallecimiento de la reina, la Curia mantuvo el título de Católico para Felipe el Hermoso y Fernando de Aragón, pero reservó a éste último el de "rey de España", contra el parecer del bando felipista. Sobre la dimensión histórica y política del concepto de España en el reinado de los Reyes Católicos véase el citado trabajo de José Manuel Nieto Soria.

117 Fernández de CóRdova Miralles, Imagen de los Reyes Católicos..., pp. 339-341. Y la reciente aportación de Marc MaYer Olivé, "El prefacio de Juan Annio de Viterbo a su obra: oportunidad e intención política", $V$ Congreso Internacional de Humanismo y Pervivencia del Mundo Clásico. Homenaje al profesor Juan Gil (en prensa).

118 Se trata de la oratio pronunciada por Oliviero en los funerales de la reina celebrados en Tarento en 1505, donde se insiste en que el título no se concedió por oculta solicitación o como un don gratuito ("per taciti preghioy per dono gratuito") sino por la propia virtud, propios méritos y obras piadosísimas de los soberanos; agradezco a Ivan Parisi la noticia y el texto de este interesante discurso conservado en la Biblioteca Nazionale di Napoli; In memoria della Catholica Regina Elisabeth, ff. 257r-279r. Ver el análisis matizable de John M. McManamon, "Catholic Identity and Anti-Semitism in a Eulogy for Isabel the Catholic", The Journal of Ecumenical Studies, 42 (2007), pp. 196-216.
} 
definían su identidad monárquica ${ }^{119}$. Así parece indicarlo el regidor Garci Rodríguez de Montalvo, tan vinculado al ideario de los soberanos, al poner en boca del héroe Esplandián la preferencia del título de "cathólico" a cualquier otra designación terrenal, "considerando él que seyendo cathólico sería amigo de Dios, [y] havría conocimiento ser en aquellos grandes imperios y señoríos su lugarteniente, su visorrey, temerlo e servirlo, tratar su gran estado no como suyo d'él, mas como quien prestado lo tenía, esperando dar muy estrecha cuenta al su Señor recordándose de la triste muerte, del temeroso infierno y del glorioso Paraíso" 120 . Más allá de las razones coyunturales, este texto resulta especialmente revelador de la autocomprensión de un título que apuntalaba el carácter vicarial de la realeza desde una perspectiva escatológica, en virtud de la cual el poder se concibe como un don entregado en préstamo, que debía ejercerse "no como suyo d'él" sino bajo las coordenadas religiosas que conducen al fin último del hombre.

El auxilio militar prometido por Isabel y Fernando se cumplió dos meses después de la concesión, cuando las tropas del Gran Capitán se desplazaron a Roma para reconquistar la fortaleza rebelde. El recibimiento triunfal otorgado el 15 de marzo al lugarteniente de los Reyes Católicos, constituyó el refrendo ceremonial de la liberación de la Urbe y la gestación de la nueva presencia hispana en la ciudad de los papas. A los relatos tardíos de Paolo Giovio y Giovan Battista Valentino, el Cantalicio ${ }^{121}$, cabe añadir el testimonio de Domingo de Zaragoza, que fue testigo del recibimiento al nuevo Liberator urbis ${ }^{122}$. Consistió en un espléndido desfile militar encabezado por la infantería, mil caballeros,

\footnotetext{
119 Véanse, por ejemplo, las instrucciones del rey Católico a Pedro Navarro sobre los conciertos con Muley Audala, ordenándole que no emplee el título de rey de Bugía, "porque el título de Bugía está ya puesto por nuestro en las memorias de la Iglesia Romana y arrimado a los otros nuestros títulos Reales"; instrucciones del rey Católico a Pedro Navarro, mayo 1510; en CODOIN, vol 37, Madrid, 1860, p. 563.

${ }^{120}$ Cfr. Emilio José SAles Dasí, "Garci-Rodríguez de Montalvo, regidor de la noble villa de Medina del Campo", Revista de Filología Española, 79-1/2 (1999), pp. 123-158; Gómez Redondo, Historia de la prosa de los Reyes Católicos..., vol. II, pp. 1797-1806. Y las indagaciones de Nicasio Salvador Miguel, "Garci Rodríguez de Montalvo, autor del Amadís de Gaula", en José Manuel Fradejas Rueda, Deborah Anne Dietrick, María Jesús Díez Garretas, y Demetrio Martín Sanz (coord.), Actas del XIII Congreso Internacional de la Asociación Hispánica de Literatura Medieval (Valladolid, 15-19 de septiembre de 2009): In Memoriam Alan Deyermond, Valladolid, Universidad de Valladolid, 2010, pp. 245-284.

${ }_{121}$ Paolo Giovio, La vita di Consalvo Ferrando di Cordova detto il Gran Capitano, trad. de L. Domenichi, Florencia, Lorenzo Torrentino, 1550, pp. 66-67. Se reproduce el diálogo entre el papa y el Gran Capitán en Giovan Battista Valentino, Cantalicio, De bis Parthenope, ed. de Sigismundum Mayr, Nápoles, 1506. Y la descripción de la Crónica manuscrita en Antonio Rodríguez Villa (ed.), Crónicas del Gran Capitán, Nueva Biblioteca de Autores Españoles, vol. X, Madrid, Bailly/Bailliere, 1908, pp. 295-296. Cfr. el análisis literario de Isabella Nuovo, Il mito del gran Capitano. Consalvo di Cordova tra storia e parodia, Bari, Palomar, 2003, pp. 53-57.

122 Véase el cap. 259, titulado "Cómo el grande capitán yspano vino, mandando el papa, en las tierras de la Ecclesia, y cómo empués huvo el triumpho complido de la fortaleza de Ostia con la entrada de Roma mucho acabadamente e con todo orden, para bien notar e bueno"; pertenece a la Historia del pontificado de Alejandro VI hasta 1501, Gerona, Biblioteca del Seminario Diocesano, ms. 12; crónica inédita redactada a comienzos del siglo XVI por Domingo (i...?) de Zaragoza, probablemente un clérigo -tal vez curial en Roma- que tenía acceso a documentación cancilleresca y debió ser testigo presencial de algunos de los hechos que narra. Edición en curso en la Biblioteca Borja (Valencia), a cargo de Maria Toldrà, a quien agradezco el texto y las indicaciones documentales.
} 
hombres de armas con sus pajes y la guardia pontificia con las trompetas que "fazían su sonada corta e agra pertenesciente a guerra", mientras "otros sonavan a la bastarda". Tras las banderas reales, con el "pendón o standarte, la meytat verde y la otra burel de seda divisa, miraglosa cosa era a la castellana", era conducido Menaldo de Guerre -capitán de la fortaleza rebelde- custodiado por ochos palafreneros y seguido por su captor, el Gran Capitán, que cabalgaba entre el duque de Gandía y el señor de Pésaro. Domingo de Zaragoza lo describe de "maravilloso aspecto [...] e muy buena edat", vestido con ropa corta dorada y montado a la jineta sobre un caballo blanco, y no en arnés de guerra que algunos consideraban más lucido. Hubo descargas de artillería al pasar delante del Castel Sant'Angelo y una recepción consistorial por el papa y los cardenales ${ }^{123}$.

Marineo Sículo dio a aquellos hechos una lectura humanística en su De Hispaniae laudibus (c. 1496-1497), considerando que el triunfo en Nápoles "muestra los bienes de España para que sea envidiada", e invita a Roma entonar sus alabanzas ${ }^{124}$. El maestro siciliano se refiere concretamente al impacto de la Fortuna hispana en la Ciudad Eterna, pues "te leerá el Sumo Pontífice y los ciudadanos de Roma, que quieren bien el nombre del rey Fernando", entre ellos su compañero Antonio Flaminio Sículo, astrónomo y poeta especialmente próximo a la natio hispana.

Siete años después, Cristóbal de Santisteban asumirá la ideología del imperium para describir aquel "reçebimiento a manera de los triunfos con que los tiempos pasados se reçebian a los principes vençedores antiguos" y la "grandissima fiesta" que le ofreció el papa, los cardenales y el pueblo de Roma ${ }^{125}$. Se fundían así los ecos de la legación pacificadora de Tendilla y las procesiones de 1492 en un contexto transformado por la nueva presencia hispana en el solar italiano: el eje Roma-Nápoles que vertebrará la política itálica de la monarquía hispana en las próximas décadas, con la Ciudad Eterna como centro legitimador de un reino napolitano que debía aportar, por su parte, la asistencia militar ${ }^{126}$.

\footnotetext{
${ }^{123}$ No nos detenemos aquí en los límites que el papa puso a estas celebraciones a raíz de las reconvenciones del Gran Capitán sobre la deriva nepotista de su política y que -según Domingo de Zaragoza- le costó al militar cordobés la rosa de Oro; Historia del pontificado de Alejandro VI, cap. 259. Este testimonio contradice el de Guicciardini, Zurita y Lorenzo de Padilla, que dan por otorgada esta joya el tercer domingo de Cuaresma; Lorenzo de Padilla, Crónica de Felipe I llamado el Hermoso, ed. M. Salvá y P. Sainz de Baranda, en Colección de Documentos Inéditos para la Historia de España, vol VIII, Madrid, Imprenta de la Viuda de Calero, 1843, p. 34; Francesco Guicciardin, Storia d'Italia, ed. de E. Mazzali, vol. I, libro III, cap. XI, p. 340.

124 María del Carmen ramos santana, Los Carminum libri duo de Lucio Marineo Sículo: Introducción, edición crítica, Cádiz, Universidad de Cádiz, 2000, pp. 29-30. Sobre el personaje véase el importante trabajo de Teresa Jiménez Calvente (ed.), Lucio Marineo Sículo. Epistolarum familiarium libri XVII, Alcalá de Henares, Universidad de Alcalá, 2001.

125 Véase más adelante la bibliografía sobre este autor y su obra.

${ }^{126}$ La consolidación de este sistema bipolar ha sido comentada por Giovanni MutTo, "L'asse Roma-Napoli e la Monarchia degli Austrias", en Carlos José Hernando SÁnchez (coord.), Roma y España..., vol. 1, pp. 91-104; Maria Antonietta VISCEgLIA, "Napoli e la política internazionale del papato tra la congiura dei baroni e il regno di Ferdinando il Católico", en Giuseppe Galasso, y Carlos José Hernando Sánchez (eds.), El reino de Nápoles y la monarquía de España. Entre agregación y conquista (1485-1535), Madrid, Sociedad Estatal de Conmemoraciones Culturales, 2004, pp. 453-485.
} 


\subsection{Perspectivas romanas de la crisis dinástica}

Las celebraciones romanas por el fallecimiento del príncipe Juan en enero de 1498 marcaron el punto más alto de la parábola propagandística de los Reyes Católicos en la Roma de Alejandro VI. Fue el canto del cisne de una monarquía que, a partir de entonces, se vio abocada a una serie de crisis dinásticas que coinciden con la descomposición de la Liga Santa y la atracción francesa de Venecia y el Papado. Conscientes de la gravedad de la desaparición del primogénito, los agentes hispanos diseñaron un programa ceremonial que debía convertir el dramático acontecimiento en un motivo de exaltación dinástica, mediante celebraciones funerarias que se desarrollaron en Milán, Sicilia y Roma.

El antiguo agente del cardenal Mendoza, Diego de Muros III (c. 1450-1525), remitió a la Ciudad Eterna su Panegyris in obitu Johannis Hispaniae principis aportando un precioso material sobre la figura del príncipe con las claves interpretativas del acontecimiento ${ }^{127}$. Al mismo tiempo, el cardenal Carvajal dirigió a los Reyes Católicos su Epistola consolatoria, publicada en Roma en la versión latina realizada por su secretario García de Bovadilla ${ }^{128}$. Una vez más, la Ciudad Eterna acusó el impacto de los mensajes transmitidos por los procuradores: Alejandro VI cedió la capilla papal para celebrar las primeras exequias por el heredero rompiendo una tradición que no contemplaba el uso este espacio litúrgico para dignatarios que no fueran reyes; siguió a éstas la ceremonia celebrada en la iglesia de Santiago de los Españoles, decorada con un imponente castrum doloris y unos diseños ornamentales que impresionaron al maestro de ceremonias.

El embajador Garcilaso de la Vega encomendó la oratio a uno de los mejores oradores de la Curia, el humanista volterrano Tommaso Fedra Inghirami ${ }^{129}$. Durante su discurso, evitó los senderos trillados por los panegiristas y planteó una versión del nuevo Imperium oceánico de los Reyes Católicos, baluarte defensivo del Mediterráneo y potencia expansiva en el Atlántico. Atribuye a los monarcas los epítetos de propagadores de la fe cristiana en una típica asimilación de categorías imperiales romanas ("Christiani imperii

\footnotetext{
${ }^{127}$ A los trabajos citados de José Luis González Novalín y José García Oro, añádase el artículo de éste último "Las pautas de un obispo humanista: Diego de Muros III", Liceo franciscano: revista cuatrimestral de estudio e investigación, 55/166-168 (2003), pp. 404-412.

128 Tomás González Rolán, y Pilar Saquero SuÁrez-Somonte, "Un importante texto político-literario de finales del siglo XV: La Epístola consolatoria a los Reyes Católicos del extremeño Bernardino López de Carvajal (prologada y traducida al latín por García de Bovadilla)", Cuadernos de Filología Clásica. Estudios Latinos, 16 (1999), pp. 247-277; el texto completo en Tomás GonzÁlez Rolán, José Miguel Baños Baños, y Pilar Saquero SuÁrez-Somonte (ed.), El humanismo cristiano en la Corte de los Reyes Católicos: Las Consolatorias latinas a la muerte del Príncipe Juan de Diego de Muros, Bernardino López de CavajalGarcía de Bovadilla, Diego Ramírez de Villaescusa y Alfonso Ortiz. Estudio, edición y traducción, Madrid, Ediciones Clásicas, 2006, pp. 51-115.

129 Abordamos estas celebraciones y la literatura generada en Álvaro Fernández de CóRdova, y Vicente CALVo Fernández, La muerte del heredero. Liturgia y humanismo por el príncipe Juan en su marco europeo (en preparación); donde partimos del excelente estudio de Manuel Vaquero PIÑEIro, "I funerali romani del príncipe Giovanni e della regina Isabella di Castiglia: rituale politico al servizio della monarchia spagnola", en Maria Chiabò, Silvia Maddalo, y Massimo Miglio (dirs.), Roma di fronte..., vol. II, pp. 641-655.
} 
propagatores"), azote de los apóstatas ("religione aberrantium flagrum") y restauradores de la paz y la justicia en toda la costa occidental ("pacis iustitiæque omni ore occiduæ restitutores"). Se trata de un énfasis político-religioso que sustituye las antiguas pinceladas épicas por una visión integradora de un poder hispano de dimensiones oceánicas, casi universales, pues los reyes son "los mayores en poder y autoridad" (dimensión política) y "los mejores en virtud, los católicos por antonomasia en religión" (dimensión religiosa). Desde esta perspectiva, el humanista recoge la idea de la translatio studii et imperii (dimensión cultural), desarrollada en 1492, al referirse a la edad dorada que experimentan "los estudios de las bellas artes en toda Hispania" gracias al impulso de la Corona, frente a unos príncipes italianos que "persiguen a las letras por ser enemigas de sus vicios" ${ }^{\prime 130}$.

Para mostrar la "amplissima gloria" de los monarcas se enumeran sus principales hazañas (res gestae) reservando para el final sus últimas conquistas. Como sucedía en la obra de Scillatio, la campaña africana sirve de pórtico legitimador de la intervención en Italia en una línea restauracionista de la dinastía aragonesa expulsada, donde la Liga Santa se interpreta como la mejor defensa de las potencias aliadas. Con la situación italiana mínimamente reequilibrada, Inghirami vuelve la mirada a los objetivos político-religiosos aún pendientes de los Reyes Católicos, anunciando la expulsión de los musulmanes de toda Europa y la expedición contra África, donde "ya les han arrebatado islas en el mar de Libia", aludiendo a la ocupación de Djerba (Túnez) en $1496^{131}$.

El discurso también indaga en la personalidad y el carisma político de los monarcas. Quince años antes de Maquiavelo, el humanista volterrano reconoce la inteligencia (tanto ingenio) de Isabel y Fernando, pues "parecía que el devenir de los acontecimientos se convertía, no en inspirador, sino en aliado de sus decisiones". También es revelador su comentario sobre la vocación imperial y la pax hispana lograda como elementos de una propaganda que años después retomará Ludovico Ariosto en favor del emperador Carlos $\mathrm{V}^{132}$. Como sucediera con la literatura sobre el atentado de 1492, Fernando se yergue ante la tragedia como un padre heroico que asombra a los presentes por su entereza y su fe; y en un coup de théâtre propio del género epideíctico, dirige al rey una serie de exclamaciones interrogativas para remover su aparente insensibilidad, consecuencia de su fortitudo, ejemplo de los antiguos ("Paulos, Marcios, Horacios, Filipos") y modelo para los presentes, pues "no te has conformado con convertirte en vencedor de los pueblos, sino que has vencido incluso al dolor".

\footnotetext{
${ }^{130}$ Bello análisis de esta idea en Ángel Gómez Moreno y Teresa Jiménez Calvente, "Entre edenismo y emulatio clásica: el mito de la Edad de Oro en la España de los Reyes Católicos", Silva. Estudios de Humanismo y Tradición Clásica, 1 (2002), pp. 113-140.

131 Sobre la campaña militar Kenneth Meyer Setton, The Papacy and the Levant (1204-1571), vol. II: The Fifteenth Century, Filadelfia, American Philosophical Society, 1978, pp. 528 y ss; Norman Housley, Crusading and the Ottoman Threat, 1453-1505, Oxford, Oxford University Press, 2013.

${ }_{132}$ Cfr. Guillermo Serés, "Ariosto, los Reyes Católicos y la Monarchia Christianorum carolina", Revista de Indias, 52 (2011), pp. 331-364.
} 
No es difícil adivinar en la oratio la necesidad de apuntalar la potencia militar hispana ante los inquietantes cambios internacionales de las treguas hispano-francesas de Lyon (II.1498). Sin embargo, la pirotecnia retórica de Inghirami, Muros y Carvajal, no pudo ocultar los inquietantes rumores que se suscitaron ante un suceso que podía interpretarse como un castigo divino. Ésta es la opinión de Domingo de Zaragoza, curial aragonés vinculado al reino de Nápoles y autor de la inédita Historia del pontificado de Alejandro $V I$. Como testigo de los hechos, Domingo recoge el "incomparable terror" de la natio hispana al advertir "quánta mudança de senyorío los regnos s'esperavan venir por esta muerte" ${ }^{133}$. El autor aprovecha para desplegar una dura crítica contra algunos aspectos de la política de los reyes, levantando antiguas y nuevas polémicas sobre la Inquisición o la conculcación de las libertades eclesiásticas que había provocado en 1497 la suspensión temporal de la reforma de las órdenes religiosas ${ }^{134}$. A estos aspectos eclesiásticos, el autor añade las medidas "castellanistas" del rey Católico que parecían vulnerar los fueros y atribuye a la perniciosa influencia de su esposa Isabel ${ }^{135}$. En la lista de agravios figura el pago de décimas y sisas, la intromisión de los reyes en bienes eclesiásticos, o los abusos cometidos contra la rama conventual aragonesa en beneficio de los observantes que dominaban la corte ${ }^{136}$. El autor se queja del autoritarismo regio en estos campos, pero alaba su política contra los conversos, la expulsión de los judíos, la conquista de Granada y la incorporación de los maestrazgos de las órdenes militares castellanas.

Domingo de Zaragoza ofrece su interpretación de la muerte del primogénito como justo castigo al rey por los abusos cometidos con la Iglesia y el reino aragonés. Su testimonio es por tanto ilustrativo de los descontentos curiales que asomaban entre las grietas de la crisis sucesoria. No fueron los únicos, pues el propio Alejandro VI se sumó a las críticas en diciembre de 1498 con motivo del envío de la embajada de Felipe Ponce e Íñigo de Córdoba. El motivo de la legación era acabar con los excesos nepotistas del papa y recuperar la reforma eclesiástica que había emprendido tras la muerte del duque

\footnotetext{
${ }^{133}$ Así se expresa Domingo de Zaragoza, probablemente perteneciente al grupo hispano que servía en Curia; Historia del pontificado de Alejandro VI, capítulo 281.

${ }^{134}$ El cronista debía recoger las denuncias que algunos franciscanos conventuales hicieron llegar al Papa sobre el expolio de sus casas por parte de los reyes y el rumor de la promulgación de un edicto ordenando el paso de todos los frailes conventuales a la observancia, que había provocado la evasión de mil quinientos frailes a Túnez; Marino SAnudo, I diarii, vol. I, a cura di F. Stefani, Venecia, 1879, col. 816; vol. II, col. 497. Tales quejas motivaron la suspensión de la reforma con la bula Quanta in Dei Ecclesia y el breve Ut imponatur finis del 9 de noviembre de 1497, un mes después del fallecimiento del príncipe Juan. Sobre este singular episodio cfr. José García Oro, El Cardenal Cisneros. Vida y empresas, vol. I, Madrid, Biblioteca de Autores Cristianos, 1992, pp. 149-150; Fernández de Córdova, Alejandro VI y los Reyes Católicos..., pp. 615-618. La actitud tan crítica del cronista sólo se explica por la distancia temporal y física, pues debió componer su obra a comienzos del siglo XVI, tal vez en la propia Roma.

135 Sobre el gobierno de Fernando en la Corona de Aragón véanse los trabajos de Fernando Solano Costa, "El reino de Aragón durante el gobierno de Fernando el Católico", Cuadernos de Historia Jerónimo Zurita, 16-18 (1963-65), pp. 221-246; Ángel Sesma MuÑoz, Fernando el Católico y Aragón, Zaragoza, Anubar, 1979; Miguel Ángel Ladero Quesada, La España de los Reyes Católicos, Madrid, Alianza, 1999, pp. 218241; Ernest Belenguer Cebriè, Fernando el Católico: un monarca decisivo en las encrucijadas de su época, Barcelona, Península, 2001.

136 Cfr. Fernández de Córdova, y Calvo Fernández, La muerte del heredero... (en preparación).
} 
de Gandía. Como es sabido, el papa había intentado sustituir al difunto por su hermano César Borja, antiguo cardenal, como cabeza del principado laico del linaje.

Ante la oposición de los reyes, Alejandro buscó el apoyo de Luis XII para hacer viable este proyecto señorial. Intereses religiosos, con consecuencias políticas, movieron al rey Católico a preparar una embajada de choque con el apoyo de su esposa, que remitió sus propias credenciales a los embajadores ${ }^{137}$. Desde el punto de vista propagandístico interesa destacar la dimensión internacional de la legación, a la que debían sumarse los agentes de las potencias aliadas: Manuel de Portugal, el Rey de Romanos y Enrique VII de Inglaterra ${ }^{138}$. Nos hallamos ante el punto de llegada de un proceso de sensibilidad reformadora que tuvo como jalones previos las exhortaciones enviadas a Inocencio VIII sobre los abusos de la Curia o las reconvenciones que Isabel hizo llegar al papa Borja a través del nuncio Desprats en 1493. Cinco años después se eligieron, sin embargo, medios más contundentes que reflejan la autoconciencia regia de su misión religiosa y eclesial, alimentada por las competencias asumidas como defensores de la Cristiandad, protectores de los Estados Pontificios y ahora reformadores de la misma persona del papa, pasando de la reforma de la Iglesia de sus reinos (reformatio in membris) a la reforma de la Cabeza (reformatio in Capite). Es precisamente en estos años de plena actividad reformadora de Cisneros, cuando los reyes asumieron una postura particularmente radical contra el nepotismo pontificio, buscando su renovación moral como sucesor de Pedro y súbdito suyo, acercándose a aquellas profecías que atribuían al rey Católico la reforma de la Curia romana como monarca universal y colaborador del pastor angelicus ${ }^{139}$.

No podemos analizar aquí las amenazas y acusaciones que se intercambiaron los embajadores y el papa durante aquellas agitadas audiencias, que pasaron de la reunión a puerta cerrada a la apelación en consistorio público con la amenaza, según ciertas fuentes, de convocar un concilio ${ }^{140}$. Entre los reproches que españoles, portugueses y alemanes

\footnotetext{
${ }^{137}$ La carta de Isabel, en nombre propio y de su esposo, anunciaba a Alejandro VI el envío de la embajada "con tanto amor y afeçyon a vuestra persona que a nadye daríamos ventaja"; Amalia PriEto CANTERo (ed.), Cartas autógrafas de los Reyes Católicos de España Don Fernando y Doña Isabel, que se conservan en el Archivo de Simancas 1474-1502, Valladolid, Instituto Isabel la Católica de Historia Eclesiástica, 1971, pp. 67-69.

138 Antonello Coniger consigna la llegada a Roma de las cuatro representaciones diplomáticas y su audiencia ante el colegio cardenalicio, en que anunciaron al papa que "se no mutasse vita e costumi l'amoveriano del Papato per li gran mancamenti che fa, e sopporta a la Christianità"; Antonello Coniger, Cronache di Antonello Coniger gentilhuomo leccese, (960-1512), en Raccolta di varie croniche, diarij, ed altri opuscoli così italiani, come Latini appartenenti alla storia del Regno di Napoli, vol. V, Nápoles, Bernardo Perger, 1782, p. 43. Las instrucciones de Manuel de Portugal a sus embajadores para que actuaran coordinados con los agentes de los Reyes Católicos en RAH, Colección Salazar, A-11, ff. 199r-200v.

139 Cfr. Duran Grau, y Requesens, Profecia i poder al renaixement..., pp. 295-296 y 406-407. Comentamos la presencia de estas corrientes durante el pontificado de Alejandro VI en FERnÁNDEZ de Córdova, "El pontificado de Alejandro VI (1492-1503). Aproximación a su perfil eclesial y a sus fondos documentales", Revista Borja. Revista de l'Institut Internacional d'Estudis Borgians, 2 (2008-2009): [=Actes del II Simposi Internacional sobre els Borja (València-Gandia, 21-23 de novembre de 2007)], pp. 237-238; véase la dirección electrónica http://www.elsborja.org/revista.php.

140 En caso de que el papa no reaccionara, los reyes ordenaron a sus embajadores que buscaran el apoyo de los cardenales y plantearan sus exigencias en consistorio público. Domingo de Zaragoza describe las medidas del papa Borja para intimidar a los embajadores multiplicando artificiosamente la guardia pala-
} 
hicieron al papa, trascendieron especialmente los usos simoníacos y la recaudación de dinero "per via lecita e non lecita", lo que obligó a Alejandro VI a cancelar ciertos tratos con el duque de Ferrara, revocar el ducado de Benevento y prometer alejar a sus hijos de Roma ${ }^{141}$. Sin embargo, no renunció al proyecto filofrancés de César Borja, ni retomó la reforma de la Curia incoada en 1497, como exigían los embajadores de los reyes.

Ante la obstinación pontificia, los agentes hispanos modificaron su estrategia comunicativa sustituyendo sus ruidosas exhortaciones por una ostentosa reclusión, sin comparecer en los actos públicos. Se inicia así un período de oscurecimiento de la propaganda hispana, caracterizado por la ausencia de celebraciones litúrgicas por el fallecimiento de la princesa Isabel de Portugal -que contó con duelos en Sicilia y en Nápoles-, o el fin de la ediciones filo-hispanas, aunque no faltaran proyectos como el Panegírico en alabanza de la reina Isabel finalizado en Roma el 23 de julio de 1499, pero publicado diez años después en Valladolid (Diego Gumiel, 1509). No eran buenos tiempos para la imagen de los Reyes Católicos; ni siquiera en el reino de Nápoles, donde un monje denunciaba en noviembre de 1499 la ingratitud regia hacia Cristóbal Colón, "et diceva pure molte altre parole vergognose" 142 .

La degradación mediática de los monarcas, consecuencia de su eclipse internacional, duró año y medio. Su lento resurgir se produjo al reactivarse los ideales cruzadistas en el Peloponeso y las victorias del Gran Capitán en el Reame. Comenzaba entonces una nueva etapa encaminada a defender los derechos del rey Católico como señor de Nápoles. Su historia se prolongará hasta su viaje al reino partenopeo (1506-1507), tras sufrir la grave crisis sucesoria de 1504 que estuvo a punto de arruinar el proyecto dinástico. El análisis de este proceso merece un estudio detenido que reservamos para otra ocasión.

\section{Epílogo conclusivo}

A la vista del itinerario seguido, es preciso reconocer la coherencia de la evolución mediática del rey Católico, aunque en su desarrollo no faltaran momentos de crisis. Se trata de un complejo proceso que arranca con un déficit de legitimidad como primogénito de Juan II de Aragón, en un momento en que la Curia se dividía ante la guerra civil catalana y la crisis sucesoria en Castilla. La imagen de Fernando de Aragón se fue abriendo paso en el imaginario político italiano gracias a su equipo diplomático, la bandera cruzadista

tina y evitando la publicidad del acto; cfr. Fernández de CóRdova, Alejandro VI y los Reyes Católicos..., pp. 395-401; ID., "Alejandro VI y los Reyes Católicos. Afinidades y diferencias al final de un pontificado (1498-1503)", en Ximo Company, Vicente Pons, y Joan Aliaga (ed.), La llum de les imatges, Generalitat Valenciana, Valencia, 2007, pp. 287-299. Los relatos de Domingo de Zaragoza, Historia del pontificado de Alejandro VI, capítulo 298; Damião DE Góis, Crónica do felicissimo rei D. Manuel, ed. de J. Martins Teixeira de Carvalho y D. Lopes, Coimbra, Impr. da Universidade, 1926, pp. 69-70. Ventura Pascual Y Beltrán, "Setabenses en la corte de los Reyes Católicos", Cuadernos de Historia Jerónimo Zurita, 19-20 (1966-1967), pp. 245-247. La amenaza conciliarista en PArenti, Storia fiorentina..., vol. II, p. 232.

141 Cronache della citta di Fermo, ed. Gaetano de Minicis, Florencia, 1870, p. 233.

${ }_{142}$ Extracto de la crónica de Luigi de Rosa, recogido por Bartolomeo CAPAsso, Le fonti della storia delle provincie napoletane dal 568 al 1500, Nápoles, Riccardo Marghieri, 1902, pp. 238-239. 
alzada durante la crisis de Otranto, su compromiso con la defensa de Nápoles y la publicidad de la guerra de Granada. En este ascenso se sistematizaron argumentos religiosos que debían desmontar los prejuicios de la Santa Sede hacia el uso de rentas eclesiásticas, los nombramientos beneficiales y la política inquisitorial. Se contó con unos medios cada vez más sofisticados que, desde los limitados recursos de la primera época, evolucionaron hacia una retórica cada vez más contundente en Roma y una producción épica y dramática elaborada por italianos implicados en el proyecto político de la Corona.

En 1492 se alcanza un cénit y un cambio de paradigma en la Roma de Alejandro VI. El perfil bélico adquirió nuevos contornos pacifistas y evangelizadores que buscaban el contraste frente a la expansión militar de Carlos VIII. Es el Fernando "preservado" de las fuerzas del mal y erigido en nuevo líder de la Cristiandad que, en un singular juego de espejos, se erigió en alternativa política al invasor francés y, a la postre, vencedor en la pugna de mesianismos políticos durante la contienda. Los dramas humanísticos y los tratados compuestos en la Curia facilitaron que el icono fernandino dibujado durante la campaña granadina evolucionara hacia el de salvador de Italia (salvator Italiae) y protector de un Papado que coronaría este ascenso con la concesión del título de rex Catholicus, junto a su esposa. Roma volvió a ser el observatorio más avanzado en la percepción de este progreso mediático que encontró en la expansión africana y los casamientos de los infantes nuevas vías de expresión de un poder cada vez más universal.

Las crisis sucesorias de 1497 y 1499 comprometieron, sin embargo, la imagen internacional de los Reyes Católicos. La reactivación militar francesa con la conquista de Milán y las pretensiones sobre Nápoles les obligaron a replegarse, perdiendo el apoyo de un Papado cada vez más refractario a sus iniciativas reformadoras. Consecuencia de ello fue la debilidad mediática de los monarcas, incapaces de hacer frente a las acusaciones de traición hacia la dinastía napolitana que hasta entonces se habían comprometido a defender. Gracias a su acción militar en el mediterráneo oriental y a las victorias del Gran Capitán en la segunda campaña de Nápoles, su imagen logró recuperarse lentamente iniciando una nueva etapa caracterizada por la defensa de sus derechos napolitanos en poemas, tratados y comedias humanísticas impulsadas desde la corte hispana y partenopea. Sin embargo, no será Isabel, sino Fernando quien culminaría este proceso durante su regencia no sin antes vencer la resistencia francesa, la disputa de su yerno Felipe de Habsburgo y los recelos de Julio II. Su viaje a Italia en 1506-1507 y las conquistas norteafricanas de 1506-1510, confirmaron su dominio sobre Nápoles y la vocación mediterránea de una monarquía preparada para asumir los contornos imperiales de Carlos V.

Con sus continuidades y sus fracturas, el itinerario iconológico de Isabel y Fernando merece una última reflexión sobre las razones de su éxito, que deben buscarse en la confluencia de tres líneas de acción: la búsqueda de una identidad política, el diseño de una propaganda en creciente desarrollo y la voluntad de ajustarse a la imagen emitida buscando la sintonía ideológica con la Roma papal. La conjunción de estos tres factores otorgó al rey un extraordinario prestigio que León X hará fijar en su representación de las estancias vaticanas con los títulos Rex Catholicus Christiani Imperii Propagator. 
No eran palabras vacías. Constituyen el reconocimiento de una acción político-religiosa que no tiene precedentes en nuestra historia. Estas páginas han querido reconstruir este patrimonio que puede considerarse una de las aportaciones más sugestivas al imaginario político de la Modernidad.

Fecha de recepción: 9 de enero de 2014

Fecha de aceptación: 6 de diciembre de 2014 